\title{
«SACAR LA SUSTANCIA AL REINO». COMERCIO, CONTRABANDO Y CONVERSOS PORTUGUESES, 1621-1640
}

por

\author{
BERNARDO JOSÉ LÓPEZ BELINCHÓN \\ Universidad de Alcalá de Henares
}

RESUMEN: En este articulo se pone de relieve el importante papel desempeñado por los mercaderes conversos lusos en el comercio ilegal que se desarrolló como consecuencia de la política de bloqueos comerciales desarrollada por la Monarquía Católica, inicialmente contra las Provincias unidas y, más tarde, sobre Francia y Portugal. Las casas de negocios portuguesas aprovecharon la ruptura de la tregua con Holanda, en 1621, para convertirse en el cauce adecuado para el desarrollo de un importante contrabando al contar con una sólida red comercial situada en los puntos clave de las rutas comerciales, de Ámsterdam a Madrid, y con el control de algunas de las aduanas más importantes. El análisis de las rutas, de las personas implicadas y de los métodos para desarrollar este comercio fraudulento en diversos momentos arroja más luz sobre el papel de los conversos portugueses. Los intentos de la Corona por yugular este trafico se vieron saldados con el fracaso por la venalidad de los oficiales reales, la predisposición a perdonar a los contrabandistas a cambio de jugosos donativos y a la gran demanda de los productos importados del norte de Europa. La concesión de licencias para importar productos de potencias enemigas, y los subsiguientes abusos, supuso un cierto reconocimiento de este fracaso. La participación en este contrabando fue básica para el enriquecimiento de las casas de negocios de los conversos procedentes del nordeste luso quienes pronto pasaron a integrarse en el negocio de los arrendamientos de rentas reales. Sin embargo, estas actividades generaron una intensa corriente de opinión que culpó a los negociantes conversos lusos de «sacar la sustancia al reino» en beneficio de sus enemigos.

Palabras Clave: Conversos. Judíos portugueses. Contrabando. Comercio. Holanda. Castilla. Felipe IV. Embargo. Monarquía Hispánica. 
ABSTRACT: In this article, we see the important role that the Portuguese conversos played in the illegal trade that developed as a consequence of the commercial blockade politics deployed by the Spanish Monarchy, initially against the United Provinces and, later, over France and Portugal. The Portuguese business bouses used the breaking of the truce with Holland in 1621 to become a channel for the development an important contraband trade. They had a commercial presence along the key points of the commercial routes from Amsterdam to Madrid and controlled some of the most important custombouses. Analysis of the routes, the people involved and the methods to develop this smuggling trade gives us a clearer view about the role of the Portuguese conversos. The attempts of the monarchy to break this traffic proved unsuccessful because of the venality of the royal officials, the predisposition to forgive the smugglers in return for a share of the profits, and the powerful demand for imports from northern Europe. The concession of licenses to import products from the enemy powers, and the subsequent abuses, entailed recognition of this failure. The participation in this contraband was essential for the enrichment of the business bouses of the conversos that came from the nortbeast of Portugal and soon integrated in the business of rent farming. However, these activities generated intense opposition, blaming the Portuguese converso merchants of draining the kingdom to the benefit of its enemies.

KeY words: Conversos. Portuguese Jews. Contraband. Commerce. Holland. Castile. Philip IV. Embargo. Spanish Monarchy.

A principios de abril de 1621 expiró la tregua entre la Monarquía Católica y Holanda ${ }^{1}$. Los navíos holandeses se vieron obligados a abandonar los puertos hispanos y todo lo poseído o manufacturado por súbditos de las Provincias Unidas fue embargado. El reinicio de las hostilidades supuso el término de una etapa en el comercio hispano-holandés y abrió otra nueva que exigía la reorganización de las redes comerciales de aquellos mercaderes dispuestos a arrostrar los riesgos que conllevaba un comercio ahora ilícito, pero lucrativo. La nueva coyuntura ofrecía a las familias de negociantes portugueses una buena oportunidad de obtener sustanciosos beneficios dada su posición en las redes comerciales atlánticas. La tupida red de vínculos familiares, personales, comerciales, de paisanaje o incluso religiosos que unía a los portugueses peninsulares con los que residían en Francia y los países del Norte los convertía en el arcaduz idóneo para unos negocios que exigían, al mismo tiempo, secretismo y confianza entre las partes para llegar a buen término.

Desde 1593 existía una pequeña colonia de portugueses en Ámsterdam que fue creciendo al calor de los buenos negocios que durante la tregua les ofrecieron sus conexiones peninsulares ${ }^{2}$. En 1612 se constata la presencia de

${ }_{1}$ Utilizaremos el termino Holanda para referirnos al conjunto de las Provincias Unidas aun cuando estas englobaban a más provincias.

2 En 1595, Baltasar Rodríguez, antiguo vecino de la villa manchega de La Roda, llegó a Ámsterdam huyendo de la Inquisición de Cuenca. CARRASCO, R: «Preludio al «siglo de los portugueses». La Inquisición de Cuenca y los judaizantes lusitanos en el siglo XVI». Hispania (Madrid) 166 (1987)

Hispania, LXI/3, núm. 209 (2001) 1017-1050 
mercaderes portugueses naturales de Trancoso en Ámsterdam en conexión con sus parientes en la Mancha ${ }^{3}$. Durante la Tregua de los Doce Años (16091621), muchas casas de negocios lusas participaron del incremento del comercio holandés con la Monarquía hispana ${ }^{4}$. También muchas de las actividades de fraude y contrabando practicadas con asiduidad por los holandeses se hicieron en conexión con mercaderes conversos portugueses. Numerosos negociantes judeoconversos lusos como Jorge Enríquez, Fernando Montesinos o Juan Núñez Saravia ya había participado desde antes de 1621 en operaciones comerciales, legales e ilegales, con Holanda como la entrada de moneda falsa y la saca de plata vía Francia. Los benéficos obtenidos con todas estas actividades, lícitas e ilícitas, permitieron a los holandeses realizar mayores inversiones en navegación y comercio, que les proporcionaron una mayor ventaja sobre sus competidores británicos o hanseáticos 5 a la par que enriquecían a aquellas casas de negocios portuguesas con capacidad para participar en ellas.

El reinicio de la guerra supuso el brusco final de esta situación. Sólo el contrabando permitiría continuar tan fructíferos negocios, pero para ello era necesario un reajuste de los canales comerciales a fin de eludir las trabas de los agentes reales. Este comercio ilegal, pese a los riesgos que implicaba para los participantes en él, reportaba suficientes beneficios como para resultar muy atractivo. La posición de muchas de las casas de negocios lusas, a caballo entre la península y Holanda y con conexiones en Francia y otros puntos, hicieron que creciese enormemente su papel a partir de 1621, al ser las mejor situadas para llevar a cabo el comercio ilegal a que obligaba el bloqueo económico impuesto por la Corona española a las Provincias Unidas ${ }^{6}$.

pp 503-559. Sobre la evolución de la comunidad sefardita en Ámsterdam en los primeros tiempos véase FRANCO MENDES, D: Memorias do estabelecimento e progresso dos judeus portuguezes e espanhoes nesta famosa cidade de Ámsterdam. Ámsterdam 1772, edición facsímil Lisboa 1.991 y MENDES DO REMEDIOS, J: Os judeus portugueses em Amsterdam. Coimbra 1911, edición facsímil Lisboa 1.991.

3 Archivo Diocesano Conquense (ADC) Inq. Leg 389, expt 5539. Rodrigo Márquez, natural de Viseu, residía en San Clemente, en la Mancha conquense, desde 1605. Su padre y uno de sus tíos, naturales de Trancoso, vivían en Ámsterdam como mercaderes. Su oficio era el de lencero dedicado a acudir a ferias como la de Mondéjar y a vender en zonas cercanas a San Clemente.

${ }^{4}$ CAStillo Pintado, A: «El gran comercio: puertos, rutas y trafico» en Historia de España fundada por R. Menéndez Pidal, Vol. 23, p. 337. Madrid 1989

5 ISRAEL, J.I.: «Un conflicto entre imperios: España y los Países Bajos. 1618-1648.» en ELliot, J.H. (ED): Poder y sociedad en la España de los Austrias. Barcelona 1982, pp 149-150. Un buen ejemplo de estas rutas de contrabando en CARRASCO VAZQUEZ, J: «Contrabando moneda y espionaje (el negocio del vellón:1606-1620)» en Hispania (Madrid) 197 (1997) pp1081-1105.

${ }^{6}$ En diferentes obras Israel ha insistido sobre este aspecto. Para él la ruptura del comercio con España a causa de la guerra hizo aumentar la importancia en la vida económica del noroeste de Europa de la diáspora conversa con sus centros en Ámsterdam, Hamburgo y Bayona unidos por tupidos lazos familiares con los cristianos nuevos de España. Estos lazos permitieron la creación de una importante red de contrabando que dio a los sefarditas holandeses una importante ventaja sobre otros comerciantes. La judería europea en la era del mercantilismo 1550-1750. Madrid 1992. pp. 134-135 y «Spanish wool export and the European economy. 1610-1640» en The economic History 


\section{A) LA RED DE CONTRABANDO DE 1621}

El 22 de junio de 1621, apenas dos meses después de expirar la tregua, Miguel de Manchola, administrador de la renta de los puertos secos de la mar, escribió una carta al Consejo de Hacienda. En ella, al igual que en otras anteriores, informaba de las sospechas que tenía sobre los arrendadores de los puertos secos altos, en particular del portugués Juan Núñez Vega. A Núñez Vega, según la carta, le era muy fácil hacer llegar mercancías holandesas a Francia y desde allí introducirlas en Castilla por Navarra a través de los puertos que él administraba, máxime teniendo en cuenta que «los más tratantes son portugueses como él y sus partícipes [en la renta]» 7 . Este no fue el único testimonio que se recibió en Madrid a cerca de este tráfico fraudulento.

Ante estas noticias, el Consejo de Hacienda decidió iniciar una investigación sobre el tema. Manchola comenzó su averiguación pública entrevistando testigos en Logroño, Vitoria y Najera, puntos todos ellos muy próximos a los puertos por donde entraba el presunto contrabando. Al mismo tiempo, el licenciado Lazón, comisario del Santo Oficio en San Sebastián, recibió encargo de realizar una pesquisa secreta, siguiendo un cuestionario muy detallado remitido desde Madrid. En él se mostraba especial interés por la participación de portugueses, residentes en la península y fuera de ella, en este tráfico y por los caminos de entrada de mercancías, especialmente las originarias de «Olanda y Zelanda», desde Francia ${ }^{8}$. Los informes recibidos fueron muy preocupantes. Diversas fuentes confirmaban la asidua presencia en San Juan de Luz y Bayona de navíos, a veces hasta ocho a un mismo tiempo,

«cargados de fardeles de mercaderías de Olanda y Zelanda y que la dicha mercaduría es de mercaderes portugueses que residen en las dichas provincias [rebeldes] y de otros flamencos y franceses y que es para otros mercaderes portugueses de España, Madrid, Valladolid y otras partes y que han pasado acá desde San Juan de Luz por vía de Navarra y de allí se encaminan por los puertos secos de Logroño, Agreda, Cerbera y los demás». Y se llegaba a la conclusión de que

\footnotetext{
review (Cambridge) XXXIII, $\mathrm{n}^{\circ} 2$ (1980), pp. 193-211. F. Ruiz Martín también apunta cómo los judíos holandeses sirvieron «de cauce en el lapso decisivo de 1627 a 1647 al flujo de plata española» hacia Ámsterdam. RuIz MARTIN, F.: «La banca en España hasta 1792» en El Banco de España. Una historia económica. Madrid 1970. p. 128.

7 «le seria muy fácil bacer venir sus mercaderías a Francia y de allí meterlas en Castilla diezmándolas en sus puertos». Archivo general de Simancas (AGS). CJH. Leg 592. 22/VI/1622.

${ }_{8}$ No fue esta la primera vez que se empleó al Santo Oficio y a sus agentes en estos menesteres. Una disposición real de 30/I/27 ordenaba a la Inquisición la vigilancia del contrabando de oro y plata hacia Francia y la entrada de vellón falso. La justificación de esta medida era que con este comercio fraudulento se debilitaba a la Monarquía Católica «único amparo de la religión católica». ADC. Inq. Lib 222.
}

Hispania, LXI/3, núm. 209 (2001) 1017-1050 
«el daño viene por haber arrendado la renta a portugueses los cuales [son] los que más tratan en las dichas islas»?.

Una Real Cedula de 14 de febrero de 1622 encomendó a D. Antonio de Portillo la realización de nuevas averiguaciones con profundidad. En el transcurso de estas constató como, desde el reinicio de la guerra, las mercancías holandesas llegaban a los encomenderos de San Juan de Luz y otros puertos del suroeste francés y desde allí pasaban a Castilla y recomendó al Consejo que «se pongan aduanas de mar en los puertos más principales entre Castilla y Aragón (...) y se (...) reconozcan las mercaderías y de las que fueren de por la mar cobren los derechos y los dejen pasar y los que fueren de Islas rebeldes las denuncien y hagan castigar» ${ }^{10}$. La aplicación de estas medidas no surtió el efecto deseado y, por una nueva Real Cédula de 22 de septiembre del mismo año, el Consejo de Hacienda dio comisión al licenciado Fernández de Castroverde para «la averiguación y castigo de los culpables en baber metido mercadurías de contrabando desde San Juan de Luz y Bayona de Francia por el reino de Navarra y puertos secos de Castilla» ${ }^{11}$. El informe resultante fue presentado en marzo de 1623 ante la Junta del Almirantazgo que se reunía en los aposentos del marqués de Montesclaros. Los datos obtenidos eran evidentes y por fin permitían recomponer la red de contrabando y sus integrantes, en especial sus ramificaciones en Castilla con más de una treintena de comerciantes portugueses identificados ${ }^{12}$.

Fernández de Castroverde averiguó que desde agosto de 1621, poco después de que el portugués Juan Núñez Vega se hiciese cargo de los puertos secos de la raya de Navarra y Aragón, hasta noviembre de 1622 habían atracado en Bayona y San Juan de Luz treinta navíos con mercancías valoradas entre 500.000 y 800.000 ducados remitidas desde Ámsterdam, Rótterdam e Islas rebeldes ${ }^{13}$. El arrendamiento de Núñez Vega (anteriormente mercader de lanas y paños de Castilla que remitía a Holanda desde Vitoria a través de San Sebastián) se confirmaba como el origen de esta red. Esto parecía dar la razón a quienes, como Juan de Gamboa y el licenciado del Corral y Arellano, se habían opuesto a la concesión de la renta a éste, cuando el Consejo de Hacienda discutió su adjudicación, por ser portugués «y lo mucho que se aventura en que las llaves maestras de la entrada y salida destos reinos, como lo son las aduanas de la dicha renta, se fien a portugueses sabiéndose el mucho oro y plata que sin licencia (...) se saca destos

9 AGS. CJH. Leg 592.

${ }^{10}$ Ibíd.

11 Ibíd.. Estado. Leg 2847. 4/III/23.

${ }^{12}$ LÓPEZ BELINCHÓN, B.J.: Honra libertad y hacienda. Próxima publicación por el Instituto Internacional de estudios sefardíes y andalusíes de la Universidad de Alcalá. En este libro se abordan con más detalle las redes de contrabando portuguesas, su papel en el capitalismo portugués y su relación con la Corona.

${ }^{13}$ Los navíos habían traído cera, clavo, pimienta, holandas, cambrays, lienzos, bayetas, goma, gamuzas y polvos de azul, AGS. Estado. Leg 2847. 4/III/23.

Hispania, LXI/3, núm. 209 (2001) 1017-1050 
reinos por su mano, medios e industria y la gran cantidad de moneda de vellón falsa que meten de fuera» ${ }^{14}$.

Las mercancías eran remitidas por comerciantes portugueses que residían en Holanda como Diego Fernández Díaz, Rodrigo Fernández Navarro (alias Jacob Navarro), Diego Martínez y Matías Rodríguez. En Francia eran recibidas por Juanot Aranadelt (alias Pie de palo), holandés residente en San Juan de Luz, y por Álvaro Luis y su hijo Jacome Luis, portugueses ambos, vecinos de Bayona. Los tres habían sido durante la tregua encomenderos en puertos vascos, como San Sebastián y Bilbao, de las mismas personas con quienes se correspondían ahora desde Francia, e, incluso, Álvaro Luis se había visto envuelto en 1609 en la evasión a Francia de la hacienda de los moriscos expulsados de España ${ }^{15}$. Su misión en los puertos galos consistía en facilitar pasaportes falsos a lo recibido de Holanda y encaminarlo hacia Castilla, bien por los puertos vascos, bien por Navarra y los puertos secos de Castilla. Esta última ruta, gracias a sus contactos, ofrecía también la posibilidad, ampliamente usada, de pasar las mercancías por los puestos aduaneros sin declararlas, lo que hacía que el viaje fuese más atractivo por allí que por San Sebastián, pese a la mayor comodidad de la ruta marítima. El licenciado Fernández de Castroverde calculaba que los portes del traslado de las mercancías por tierra ascendían a 60 reales frente a los 8,5 que costaban por San Sebastián hasta Vitoria, diferencia que sólo era posible amortizar eludiendo el pago de los derechos aduaneros en la vía terrestre ${ }^{16}$.

Juan de Zabalza, vecino de Pamplona y arrendatario de la renta de las tablas de Navarra, era el principal encargado del tramo navarro de la red de contrabando. En un informe sin fecha que se conserva entre los papeles del Consejo de Estado se decía que se había comprobado que las mercancías rebeldes que entran en estos reinos se descargan en Francia " $y$ por el puerto de Vera entran en Pamplona dirigidas a Juan de Zabalza arrendador de las tablas de aquel reino y este les bace un buen pasaje por la correspondencia que tiene y con memoria suya las dejan pasar a Castilla por los puertos de Agreda y Cervera». Zabalza se hacía cargo de las mercancías que entraban desde Francia por Maya, El Burguete e Irún. Su posición era especialmente ventajosa por coincidir en él su condición de navarro, lo

${ }^{14}$ Ibid. CJH. Leg 592. Numerosas referencias sobre los aduaneros portugueses en DomINGUEZ OrTiz, A.: Politica y hacienda de Felipe IV. Madrid 1960 (1983) pp. 198 y 199. En esta obra se cita una consulta del Consejo de Hacienda de 24/VII/1622 que habla de «la mala opinión que los de esta nación que tratan en arrendamientos y mercaderías tienen de que a vueltas de ellos sacan sin licencia mucho oro y plata destos reinos y los envían a otros de su nación que buidos de la Inquisición residen en La Rochela y otros puertos de Francia y en otros reinos» p. 123. Pero ya antes otros portugueses habían arrendado aduanas reales como Diego Núñez Acosta, administrador de los Almojarifazgos de Sevilla y sobreguarda mayor de mar y tierra de Indias de 1602 a 1607 y administrador de los puertos secos con Aragón y Valencia de 1607 a 1610.

15 AHN. Inq. Leg 171, expt 4.

16 AGS. Estado. Leg 2847. A los mayores costos de los portes por vía terrestre había que sumar teóricamente el pago de un $5 \%$ en la aduana de San Juan de Luz, un $8 \%$ en las aduanas navarras y un $10 \%$ en las de Castilla.

Hispania, LXI/3, núm. 209 (2001) 1017-1050 
que le eximía del pago de derechos de entrada de mercancías, y de administrador de la renta que cobraba los derechos de salida de las mercancías hacia Castilla. Otro navarro involucrado en estas actividades era Pedro Fernández, también tablajero.

Existía una completa sintonía entre Zabalza y su colega Núñez Vega, arrendatario de los puertos secos del lado castellano. Así queda de manifiesto en la carta que aquel dirigió a éste en la que le pedía "que si pudiese sacar declaración (...) para que los fustanes, bocacíes y cera pasasen como mercaderías de Alemania $y$ las bayetas (...) de Inglaterra, la goma (...) de Levante, y lo que toca a navales, grosería, arpilleras, corchetes y gamuzas (...) de Francia» ${ }^{17}$. La petición por parte del navarro de pasaportes falsos para mercancías holandesas indica la complicidad entre ambos aduaneros en el fraude. Si no podían conseguirse los pasaportes no era difícil lograr pasar las mercancías a Castilla por trochas y veredas, evitando los controles aduaneros. La mutua confianza llegaba hasta el extremo de despachar sin reconocer en las aduanas de Castilla muchas de las mercancías enviadas por el navarro.

Al otro lado de la frontera Juan Núñez Vega jugaba un papel básico por su control de las aduanas castellanas de la zona. Diego Fernández Díaz, en una carta escrita en noviembre de 1621 desde Ámsterdam a su agente en Bayona, Álvaro Luis, insistía en que «es necesario que vuestra merced con esos señores arrendadores haga un asiento muy acomodado para que podamos por abi navegar (...) algunas mercadurias» ${ }^{18}$. El acuerdo no fue difícil pues, amén de intereses comunes, Núñez Vega mantenía antiguas relaciones de amistad con Álvaro Luis y otros encomenderos instalados en Francia a quienes conoció y trató durante los años de la Tregua en los puertos vascos ${ }^{19}$. La administración de cada una de las aduanas que integraban el partido de puertos altos estaba encomendada, hasta donde sabemos, a compatriotas portugueses de Núñez Vega y también conversos como él. Tal era el caso de las aduanas de Agreda, Logroño, Cervera, Arcos y Alcanadre. Los puestos de mayor responsabilidad recaían en personas unidas a él por lazos de parentesco, como su cuñado, Manuel Núñez Olivera, en el puesto de Cervera o su propio hermano, Manuel Lorenzo Madureira, en el de Arcos. Todos ellos tenían amplia experiencia en el comercio con Francia, incluso en actividades ilícitas como la de sacar la hacienda de los moriscos o entrar moneda falsa. Miguel de Sosa, también converso portugués e involucrado en estos asuntos ilegales, era a quien Núñez Vega confiaba la administración de la renta durante sus frecuentes estancias en Madrid ${ }^{20}$.

17 Ibíd.. Carta de Juan de Zabalza a Juan Núñez Vega de 8 de noviembre de 1622.

18 Ibíd..

19 Antes de tomar la renta, Núñez Vega residió en Vitoria dedicado a remitir paños a San Sebastián y su hermano Manuel Lorenzo Madureira vivió desde 1614 en Azpeitia vendiendo mercancías, efectuando frecuentes viajes a Bayona y San Juan de Luz.

20 AHN: Inq. Leg 62, expt 5. Se le acusó de haber pasado hacienda de moriscos a Francia y de traer moneda falsa a Castilla. Luis Hernández, arriero que había trabajo para Álvaro Luis, conoció 
El daño que estas actividades del arrendador y sus agentes provocaban a los intereses de la hacienda real era muy importante. Las mercancías, además de ser holandesas, pagaban menos derechos. Era frecuente cobrar menos varas o libras de las que contenían los fardos, "en la lencería y cargas de navales que ordinariamente se diezman por 1.000 anas aquí se bacen por 500 y los fardos de 16 anas por $8 »^{21}$. Otras cargas ni tan siquiera pagaban. El buen funcionamiento de esta red y las facilidades aduaneras de que gozaba explican el extraordinario auge del comercio entre Navarra y Castilla desde el momento en que Núñez Vega asumió la administración de los puertos. Los testigos examinados por Fernández de Castroverde declararon que en veinte años nunca habían visto «salir de Navarra para Castilla tantas mercaderias ni de aquellos géneros». Este crecimiento era paralelo al aumento de la llegada de navíos holandeses a los puertos del suroeste galo y a la entrada de mercancías desde Francia a Navarra, "que fueron tantas las (...) que vinieron que no babían visto tantas» ${ }^{22}$.

La Corona intentó controlar este tráfico estableciendo aduanas del diezmo de la mar, no controladas por arrendadores portugueses, para supervisar las de los puertos secos. Los iniciales intentos de soborno protagonizados por Zabalza fracasaron pero la posición de los administradores de los puertos secos era tan fuerte en sus villas, tenían «la justicia tan de su mano», que lograron hacer encarcelar a aquellos diezmeros de la mar que les incomodaban con molestas averiguaciones. Su prepotencia era tal que pasaban enormes cargas sin pagar derecho alguno, lo cual "babia dado muy grande estampido y se había sabido en Madrid» ${ }^{23}$.

Los destinatarios de estas mercancías en Castilla, según el informe del Licenciado Fernández de Castroverde, sumaban una treintena repartidos entre Burgos, Valladolid, Segovia y, sobre todo, Madrid. Todos los que hemos podido identificar reunían unas características comunes y casi nos permitirían hablar de una "compañía de contrabando». Todos eran portugueses y naturales de lugares próximos entre sí. Un buen número procedía de Vila Flor y Trancoso; otros de Bragança, La Guarda, Lamego o San Juan de la Pesquera, todos pueblos cercanos entre sí de las comarcas de Trás-os-Montes y la Beira interior, tierra de conversos. Esta proximidad de orígenes puede explicar las relaciones de amistad, quizás, surgidas en Portugal, que unían a muchos de ellos. Tales lazos de amistad, paisanaje y origen social se veían reforzados, y a su vez reforzaban, a los generados por intereses económicos mutuos. La mayoría había participado anteriormente en comercio exterior, lícito e ilícito, como Francisco

\footnotetext{
en Bayona a Miguel de Sosa "que había pasado a Francia mucbas cantidades de oro y plata de moriscos $y$ traía a España mucha moneda falsa de cobre».

${ }^{21}$ AGS. Estado. Leg 2847.

22 Ibíd.. Estas declaraciones las hacía un vecino que llevaba más de veinte años viviendo en la zona.

${ }^{23}$ Ibíd.. Esta queja provenía de Juan de Zabalza tras conocer que Miguel de Sosa había pasado por Agreda cuarenta cargas de mercaderías de una vez pudiéndolas haber pasado de diez en diez y con menos escándalo.
}

Hispania, LXI/3, núm. 209 (2001) 1017-1050 
de Amezquita, acusado de introducir moneda falsa por San Sebastián durante la Tregua ${ }^{24}$, o Enrique Méndez, gran exportador de lana, a quien venían dirigidas las mercancías de un navío holandés arribado a San Sebastián cinco días después de expirar la Tregua, en la primavera de $1621^{25}$.

Los vínculos familiares jugaban también un activo papel. En un entramado comercial como el descrito, los lazos familiares reforzaban la seguridad y, de este modo, muchos de los remitentes del contrabando estaban unidos por este tipo de vínculos con los destinatarios de las mercancías. Aun cuando entre ellos no conocemos relaciones de parentesco, algunos se perfilan como integrantes de poderos grupos familiares. Veamos algunos ejemplos. Juan Rodríguez Lamego era cuñado de Enrique Núñez Saravia (hermano Juan Núñez Saravia quien participó activamente en la evasión de la hacienda de moriscos y el contrabando de moneda durante la Tregua) y tío de Bartolomé Febo, ambos importantes mercaderes. Otro de los participes, Antonio Núñez Torres era suegro de los hermanos Antonio y Pedro Fernández Pato, poderosos hombres de negocios asentados en Galicia y administradores de bienes de la mitra compostelana. Por último, Diego Rodríguez de Acosta era pariente de los Tinoco, poderosos asentistas portugueses. Las relaciones parentales también se extendían fuera de la península. Antonio Núñez Torres, quien en 1637 vivía ya en Ámsterdam, era cuñado de Rodrigo Fernández Navarro, alias Abraham Navarro, quien a su vez era familiar de Manuel Núñez Navarro, otro de los receptores de los envíos ${ }^{26}$. Luis Rodríguez Lamego era pariente del rico mercader Lopo Ramírez, vecino de Ámsterdam.

Recibidas las mercancías en Madrid, o en otras ciudades castellanas, los mercaderes lusos involucrados en la red de contrabando debían hacerlas entrar en los circuitos del comercio menudo. Los tratantes portugueses, desde fines del siglo XVI, habían creado toda una trama comercial que llegaba hasta las capas más elementales del consumo castellano. El mercader itinerante que recorría «las aldeas (...) y les vendía a los labradores lienzos y fiaba» ${ }^{27}$, transportando un fardo que muchas veces le había fiado algún pariente o un mercader amigo, era el escalón inferior. Un peldaño superior estaba ocupado por los tenderos es-

${ }^{24}$ AHN. Inq. Leg 134, expt 13. Se le acusó en 1622 de ser uno de los portugueses que tenía más mercancías de portugueses de fuera de Castilla.

${ }^{25}$ ISRAEL, J. I.: «Spain and the Dutch Sephardim. 1609-1660. en Studia Rosenthaliana (Ámsterdam) 12 (1978) pp. 1-61. Las mercancías venían consignadas por judíos holandeses para el mencionado y para Francisco de Amezquita y otros mercaderes portugueses de Madrid.

26 Rodrigo Fernández Navarro era natural de Vila Flor y fue comerciante en Oporto. En 1620 partió hacia Ámsterdam desde donde enviaba mercancías a sus correspondientes, muchas veces sus propios familiares. ADC. Inq. Leg 445. expt $6292 \mathrm{E}$.

${ }_{27}$ Carrasco, R.: Preludio.. Op cit . ADC. Inq. Leg 419, expts 5875 y 5880; Leg 400, expt 5681 y Leg 399, expt 5655. Estos procesos, entre otros muchos, nos acercan a esta realidad de los lenceros ambulantes por las zonas rurales del interior de Castilla. El cruce de denuncias permite descubrir extensas redes de contactos entre estos mercaderes, aparentemente aislados, y otros de más entidad. López BELINCHÓN, B. J.: Op cit. 
tablecidos de modo permanente en los pueblos la comarca. En sus tiendas se vendían todo tipo de productos, las más de las veces al fiado o con pago en prendas, y con los beneficios obtenidos prestaban dinero a las elites locales o incluso al municipio. Desde esta base solían enviar a otros miembros de la familia, a veces el propio tendero, o a criados a vender de modo ambulante por la comarca ${ }^{28}$.

Tenderos y «mercaderes de fardo» se abastecían en las ferias que se desarrollaban por toda Castilla y que ponían en contacto las grandes rutas comerciales con los caminos campesinos, en palabras de Braudel ${ }^{29}$. Una amplia oferta de productos podían adquirirse en ellas: lienzos portugueses y gallegos, tafetanes andaluces y una amplia gama de géneros extranjeros, muchas veces holandeses. Estas mercancías eran aportadas por los agentes de los mercaderes de lonja o «mercaderes de grueso» asentados en las principales plazas comerciales. En una redada efectuada durante la celebración de la feria de Pastrana, en la primavera de 1625, por agentes del Santo Oficio de Cuenca fueron apresados un buen número de mercaderes lusos que habían acudido a ella. Entre los asistentes a la feria, aunque no fue apresado, estaba uno de los sobrinos de Fernando Montesinos, receptor de mercancías de contrabando, a quien éste había usado algunas veces como agente, seguramente intentando vender mercancías cuyo origen es fácil imaginar ${ }^{30}$. Era una práctica habitual que los mercaderes mayoristas usa-

${ }^{28}$ En el embargo de bienes de Francisco Ferrera, mercader portugués vecino de Villanueva de la Jara, en 1620 se citan varias prendas empeñadas a cambio de dinero pertenecientes a sendos regidores de la villa. Ibid Leg 399, expt 5663. Son muy numerosos los ejemplos de este comportamiento. Ibíd.. Leg 398, expt 5654 correspondiente a un vecino de Córdoba y Leg 419, expt 5880 de un vecino de Orgaz. Una vez puesto en libertad Francisco Ferrera, presentó una queja ante el Santo Oficio de Cuenca por la negativa de este a pagarle las deudas que tenia en diferentes pueblos de la comarca donde acudían a vender sus hijos. En 1630 Diego de Almeyda recordaba cómo sus padres, tenderos, «le dieron una caja con la que andaba vendiendo mercancías por la calle». Ibid. Leg 432, expt 6109.

29 BRAUDEL, F.: El Mediterráneo y el mundo mediterráneo en la época de Felipe II. 2 Vol. (1949) México 1987. Según Braudel, las ferias locales o regionales eran siempre lugar de cita de importantes mercaderes muy familiarizados con letras de cambio y el mecanismo de crédito. A estos se suman un gran número de vendedores ambulantes más modestos que aportan productos del mundo rural. Ibíd.. V.I, pp. 506-507. Cita el ejemplo de la feria de Tendilla en 1580, donde ya se observa la presencia de portugueses. SALOMON, N.: La vida rural castellana en tiempos de Felipe II. Barcelona 1964 (1982) pp. 101-102.

${ }^{30}$ ADC. Inq. Leg 419, expts 5871, 5872, 5875 y 5876; Leg 417, expt 5860; leg 416, expt 5843 y leg 415 , expt 5840 . El malsín que provocó la redada e identificó a los que había que prender fue Juan Rodríguez, portugués vecino del Toboso. Este estaba integrado en una red familiar de mercaderes y tenderos lusos apresados en su mayoría por la Inquisición conquense en 1622. Desde su base en el Toboso sus actividades comerciales abarcaban buena parte de la geografía manchega, lo cual permitió a Juan Rodríguez conocer en ferias y fondas, muchas de ellas frecuentadas tan sólo por portugueses, a los mercaderes que más tarde denunció. El eco de sus delaciones llegó incluso hasta los mercaderes de grueso de Madrid, temerosos de que a través de sus agentes las acusaciones llegasen hasta ellos. Ibíd.. Leg 728, expt 1226. Manuel López Ferro fue objeto de un intento de

Hispania, LXI/3, núm. 209 (2001) 1017-1050 
sen las ferias para redistribuir sus productos. Jorge Enríquez, hermano de Baltasar Enríquez, otro de los involucrados en la red de contrabando, decía en 1633 que «ha permanecido siempre en Madrid con salidas a Cuenca, Segovia y otros lugares por los tratos de mercancias e ir a algunas ferias» ${ }^{31}$. Aparte de las compras de lana que le llevaban a ciudades ganaderas como Segovia o Cuenca, nos consta su asistencia a ferias como las de Alcalá, Pastrana, Mondéjar y Tendilla, a la que también solía acudir otro importante mercader de grueso como Juan Núñez Saravia ${ }^{32}$. Otro hermano de Jorge Enríquez, Fernán Méndez, encarcelado en Cuenca en 1617 acusado de judaizante, había estado a su vez varios años vendiendo por la comarca conquense de San Clemente «cosas que venían de Flandes» y que le habían remitido sus hermanos ${ }^{33}$. Una vez más comprobamos la capacidad de las redes comerciales creadas por los portugueses, muchas de ellas con base familiar, para poner en relación los ámbitos del comercio internacional y los de la venta al por menor por villas y lugares.

Cuando un comerciante había logrado suficiente caudal para actuar como mercader de lonja abandonaba los enojosos viajes a las ferias y se instalaba de manera definitiva en una ciudad, preferiblemente Madrid si se era suficientemente importante ${ }^{34}$. Este cambio suponía un ascenso importante en posición económica y prestigio social «porque su negocio no era mercadante de ferias sino de lonja en su casa y corresponderse con otras ciudades» ${ }^{35}$. Esta posición, sin embargo, no hacía olvidar la venta en la propia lonja a otros mercaderes que acudían a ella para abastecerse. En el caso de Fernando Montesinos hemos conseguido identificar varias de estas operaciones. Los compradores se definían a sí mismos como mercaderes, a veces precisando su especialización como el lienzo, la seda, «la ropería» o la joyería. La mayoría de los que hemos podido identificar eran de Madrid [8] y Toledo [6]; les seguían en importancia los manchegos [5] ( La Solana, Alcázar de Consuegra, Manzanares y Membrilla) y, por último, los de Pastrana $[2]^{36}$. El promedio del valor de lo vendido es de unos 3.300 reales, con un máximo de 12.245 y un mínimo de 330 , cantidades que no solían pagarse al contado si no a plazos o a los tres meses de efectuada la compra. La

chantaje por el malsín que denunció a los mercaderes portugueses de la feria, Juan Rodríguez del Toboso, aunque parece que sin éxito.

31 AHN. Inq. Leg 144, expt 15.

32 Ibid. Leg 171, expt 4. Así lo declara Baltasar Enríquez en las defensas del proceso de Núñez Saravia. También coincidieron en la de Pastrana y en otras partes donde hay ferias y tráfico de mercancias», como por ejemplo Segovia.

${ }^{33}$ ADC. Inq. Leg 393, expt 5598 bis. Fernán Méndez formaba parte de una amplia «conspiración» extendida por toda La Mancha conquense y con relaciones comerciales y familiares con los Enríquez del Toboso, presos en 1622 tras las denuncias del malsín Juan Rodríguez.

${ }_{34}$ AHN. Inq. Leg 3773.

35 Esta declaración la realizó Núñez Saravia en su proceso insistiendo sobremanera en las diferencias entre mercader de lonja y cualquier otro tipo de comerciante. Ibid. Leg 171, expt 4.

36 Un tendero de Guadalajara declaraba en 1630 que «fue a Madrid algunas veces a comprar mercancias» para abastecer su tienda. ADC. Inq. Leg 433, expt 6122. 
mayor parte de los productos vendidos eran textiles, muchos de ellos, como gamuzas, bombasíes, holandas, cambrays, sayales, fustanes o bocacíes eran productos característicos de los telares holandeses ${ }^{37}$. Resulta bastante fácil imaginar la procedencia y el camino recorrido por estos productos hasta llegar a las manos de Montesinos y las humildes tiendas de Pastrana o Manzanares ${ }^{38}$. Además de Montesinos, otros mercaderes relacionados con la red de contrabando llevaban a cabo prácticas semejantes como Jorge Enríquez, Guillén de Soto. También mercaderes vinculados por parentesco o amistad a éstos como la madre de los Cortizos, Francisco Rodríguez Morales o Bernardo López Ferro, desarrollaban negocios muy similares, aunque no seamos capaces de determinar su grado de vinculación con la entrada fraudulenta de mercancías del exterior.

Entre los mercaderes vinculados a la red de contrabando y sus homólogos lusos era también frecuente realizar viajes a Francia. Hasta puertos del sur aquitano como Burdeos o Bayona llevaban mercancías castellanas, especialmente lanas y paños de calidad, para intercambiarlos por las allí descargadas de los navíos holandeses o bien para ajustar cuentas con sus agentes en aquellos puntos sobre las mercancías previamente remitidas ${ }^{39}$. Las investigaciones del licenciado Fernández de Castroverde también pusieron al descubierto «cómo mercaderes de Yanguas y otros sitios ban llevado muchas lanas [a Francia] trocándolas por mercadurías de contrabando» y el propio Virrey de Navarra informaba en marzo de 1624 a la Junta de Comercio de la entrada «sin límite» desde Francia de «mercadurias traídas de Olanda y Zelanda». Estas mercancías arribaban en buques neerlandeses hasta Bayona y San Juan de Luz «y como no pueden meter en España por otra parte las venden a bajos precios en dineros $y$ a trueque de lana» ${ }^{40}$. La importancia de este comercio se pone de manifiesto en numerosos memoriales de claro signo mercantilista, como los de Francisco de Retama, en los que se mostraba una fuerte oposición a la salida de lanas y otros productos «de lo que resulta hacerse negocio aqui y quitárselo a las Islas Rebeldes de Olanda y Zelanda». En

37 Glamann, K.: «El comercio europeo 1500-1750» en CiPOlLA, C. M. (Ed): Historia económica de Europa. V.II Barcelona 1979 (1981) p. 392. Las nuevas pañerías holandesas se especializaron en tejidos ligeros como sayales, bayetas y fustanes. El lienzo flamenco blanqueado en Holanda era exportado bajo la denominación de «lienzo de holanda» tanto desde Amberes como desde Ámsterdam. El doctor Diego López Téllez, hermano de Montesinos, compraba lienzos en Ámsterdam según muestran los protocolos notariales. Existe constancia de estas actividades en los registros de protocolos notariales de Ámsterdam. El doctor Diego López Téllez envió en 14/VII/21 una partida de mercancías a Manuel Sierra en La Rochelle; en septiembre compró lienzos en la ciudad holandesa, presumiblemente para remitir a España, y en 24/VIII/22 recibía lanas castellanas en Ámsterdam, llegadas vía Bayona. Pieterse, W. Ch. y KOEN, E. M. (Ed): «Notarial records relating to the portuguese Jews in Amsterdam up to 1639» en Studia Rosenthaliana (Amsterdam) 19 (1985) p.175 $\left(\mathrm{n}^{\circ} 2454\right)$ y $182\left(\mathrm{n}^{\circ} 2847\right)$ y $20(1986)$ p. $59\left(\mathrm{n}^{\circ} 2695\right)$.

${ }_{38}$ Archivo histórico de protocolos de Madrid (AHPM). Prot n1 4390, 4391 y 4392.

39 LÓPEZ BELINCHÓN, B. J.: Op cit.

40 AGS. Estado Leg. 2847.

Hispania, LXI/3, núm. 209 (2001) 1017-1050 
ellos se estimaba el valor de lo exportado de España en unos treinta millones de ducados anuales, sin incluir las lanas y los productos americanos ${ }^{41}$.

En este comercio de exportación de lanas jugaban un papel muy importante los mercaderes establecidos en aquellos puertos, muchas veces naturales de la tierra. El donostiarra Miguel de Eraso era uno de los principales agentes involucrados en este tráfico. Representaba los intereses de un buen número de portugueses como Antonio Méndez Soto y su primo Guillén de Soto, Antonio Álvarez Cerón, Enrique Méndez, involucrados todos ellos en la red de contrabando de 1621 al igual que Jácome Luis, instalado en Bayona y participante en la descrita red de contrabando. El también donostiarra Martín de Ben representaba a otro nutrido grupo de mercaderes portugueses vinculados al contrabando entre los que destacaba Fernando Montesinos ${ }^{42}$. La actividad de exportadores lusos de lana castellana era también notoria en Deva (Guillén de Soto y Enrique Méndez), Bilbao (Enrique Méndez) y Santander (Antonio Méndez Soto $)^{43}$. De este modo, la salida de lanas hacia Francia, en la que participaron otras muchas casas de negocios no involucradas en la red de contrabando, se convertía en una pieza clave en el entramado del comercio ilícito descubierto en 1623 al financiar la compra de las mercancías holandesas y, al mismo tiempo, abastecer de materia prima a las pañerías neerlandesas.

\section{B) EL FRACASO DE LA REPRESION}

La existencia de activas redes de contrabando, puestas de relieve ya en el otoño de 1623, obligaron a la creación de un organismo real encargado de perseguir el tráfico ilegal. Por Real Cédula de 4 de octubre de 1624 se creó en Sevilla el Almirantazgo de los países septentrionales. Su misión era luchar contra el poder marítimo del enemigo holandés, dentro del proyecto de guerra global auspiciado por Olivares, obstaculizando su comercio e impidiendo la entrada de sus mercancías en la Península y, al mismo tiempo, proteger de los ataques holandeses a los navíos que desde España se enviasen a los países del

${ }^{41}$ Ibíd.. Memorial de D. Francisco de Retama, vecino de Jerez de la Frontera, al Rey D. Felipe IV. Madrid 24/X/23. El autor hace un recorrido exhaustivo sobre las mercancías que salen de España y el valor de cada una de ellas.

${ }^{42}$ AGS. TMC. Leg 815. También usaron los servicios de Eraso Antonio Díaz de los Ríos, Andrés Vaz Núñez, Francisco de Acosta Fonseca, Jerónimo Fonseca, Salvador Rodríguez, Pedro Cisneros (vecino de Burdeos), Luis Olivera Lisboa, familiar de Bartolomé Febo, y Bento Rodríguez Lisboa, aún avecindado en Madrid. Los de Martín de Ben eran Antonio Fernández Castaño, Gaspar Enríquez, Domingo Coutiño y Francisco Díaz, ambos vecinos de Rioseco. Según Israel, de los 23 exportadores desde San Sebastián 10 eran cristianos nuevos, 5 de 10 en Santander y 8 de 21 en Bilbao. ISRAEL, J. I.: Spanish wool.. Op cit, p. 206.

${ }_{43}$ AGS. TMC. Leg 815. La información es muy parcial, pero creo que suficientemente significativa al ponerla en relación con otros datos. 
norte de Europa ${ }^{44}$. Esta institución sufrió un desdoblamiento de funciones con la creación el 13 de enero de 1625 de un «Consejo, Junta y Tribunal Superior del Almirantazgo» con sede en Madrid. Domínguez Ortiz habla de la existencia, a partir de este momento, de dos instituciones diferentes ${ }^{45}$. El Almirantazgo sevillano llevó una existencia mortecina que condujo a su pronta desaparición. Por el contrario, el madrileño se convirtió en una institución centralizada con agentes en toda al Península, pese a las fuertes resistencias que opusieron los reinos forales, para vigilar y reprimir el comercio con los enemigos de la Monarquía y también asumió las competencias de tribunal ordinario para las causas comerciales. Pertrechado con un arsenal legal que respaldaba su actuación ${ }^{46}$, se convirtió en el gran perseguidor de las redes de contrabando de los conversos portugueses que tanto daño hacían a una política real que intentaba la asfixia económica de Holanda. Por este motivo N. Bröens ha calificado al Almirantazgo como una "Inquisición económica» ${ }^{47}$. La Monarquía, incluso, hizo uso de otras armas más sutiles en su lucha contra el contrabando. Entre ellas nos interesa especialmente la investigación encomendada al licenciado Villadiego, secretario de la Inquisición, en las comunidades portuguesas de Francia. Este recorrió en misión secreta varios puntos neurálgicos de la ruta del contrabando con Holanda para obtener información, más de carácter económico que religioso, aprovechando los enfrentamientos entre portugueses por razones comerciales. En este mismo sentido debe situarse la disposición de 2 de febrero de 1627, por la cual los delitos de contrabando de moneda de vellón falso pasaban a jurisdicción del Santo Oficio ${ }^{48}$.

44 Dominguez Ortiz, A.: «El Almirantazgo de los países septentrionales y la política económica de Felipe IV» en Hispania (Madrid) 27 (1947) pp. 272-290; y «Guerra económica y comercio extranjero en el reinado de Felipe IV» en Hispania (Madrid) 89 (1963) pp. 70-100. ELLIOTT, J. H.: El Conde Duque de Olivares. Barcelona 1990. pp. 175, 226-230 y 301. ISRAEL, J. I.: Un conflicto .. Op cit. pp. 166-167. Sobre el contrabando y su represión HeRRERO SÁNCHEZ, M: «La política de embargos y el contrabando de productos de lujo en Madrid (1635-1673). Sociedad cortesana y dependencia de los mercados internacionales» en Hispania (Madrid) 201 (1999) pp 171-191.

45 Dominguez Ortiz, A.: Guerra económica.. Op cit. pp. 79-80. Conocer el funcionamiento del Almirantazgo, tanto el sevillano como el madrileño, en sus diferentes aspectos resulta muy difícil ante la ausencia de documentación.

46 La Real Cedula de 16 de mayo de 1628 reunía todas las anteriores, como la de 15/X/25, contra el comercio con los enemigos de la Corona. La reiteración de estas prohibiciones es un indicio de que no siempre se cumplían. Sobre la Real Cédula de 16/V/28 Dominguez OrTIZ, A.: Guerra económica.. Op cit. pp. 90-91. Muy detallado sobre la legislación contra el contrabando resulta el libro de GonZalez Salcedo, P.: Tratado jurídico-político del contrabando. Madrid 1654. En él se incluye el texto integro de la Real Cédula de $16 / \mathrm{V} / 28$, pp. 18 vto- 26.

47 BRÖENS, N.: Monarquía y capital mercantil: Felipe IV y las redes comerciales portuguesas (16271635). Madrid 1989. p. 33. ISRAEL, J. I.: Un conflicto.. Op cit. p. 167. «Los procedimientos del Almirantazgo y su tribunal transformaron definitivamente la situación en los puertos españoles (...). Los ministros de Felipe IV preferían sufrir pérdidas de tráfico e ingresos comerciales si con ello podían perjudicar a los bolandeses»..

48 ADC. Inq. Leg 222. Dominguez OrTiz, A.: El Almirantazgo.. Op cit. p. 276 y ElliotT. J. H.: El Conde Duque. Op cit. p. 309. Según Boyajian, la Inquisición velaba también por los inte-

Hispania, LXI/3, núm. 209 (2001) 1017-1050 
Pese al aumento de la vigilancia, el comercio con Holanda, tanto en su faceta del más puro contrabando como bajo una apariencia de legalidad, siguió atrayendo la atención de muchos miembros del colectivo de mercaderes de lonja y hombres de negocios lusos asentados en Castilla y con suficientes contactos en el exterior. Diversos testimonios nos hablan de la actividad de estos mercaderes. Especialmente importantes y clarificadoras resultan a este respecto las cartas comerciales que la Inquisición secuestró en 1635 a Luis Fernández Pato al tiempo de la prisión ${ }^{49}$. Esta correspondencia muestra con claridad el funcionamiento de los mecanismos comerciales de importación y exportación de la familia Pato, cuyos miembros se repartían entre Ámsterdam, Hamburgo y Castilla, y que eran utilizados para socavar la política de embargos de la Corona. Luis Fernández Pato había quedado encargado de los negocios familiares en la Península y se correspondía con sus tíos afincados en Ámsterdam a través de sus agentes en Francia, en especial su primo Pedro Lorenzo Aguiar. Este, según un testigo:

«se corresponde con Luis Fernández Pato y otros muchos portugueses de España. En Holanda se corresponde con Pedro Fernández Pato y Moisés Pato y Pedro López Torres y David Torres [alias usados por los Pato], remitiéndoles las lanas y mercancías que el dicho Luis Fernández Pato les enviaba desde España y a este las que los Patos y Torres le enviaban desde Holanda porque de ordinario hay navíos holandeses en Bayona en los que van y vienen estas mercancías» ${ }^{50}$.

reses económicos de la Corona. Portuguese Bankers at the court of Spain 1626-1650. New Brunswick 1983, p.36. Op cit. p. 117. De igual modo piensa N. Bröens, Op cit, p.117. Ya en 1623 se intentó montar un Tribunal inquisitorial en el Río de la Plata con la misión específica de vigilar a los «cristianos nuevos de la nación bebrea de los Reinos de Portugal», sus entradas y comunicaciones. El proyecto no fructificó. ISRAEL, J. I.: Spain.. Op cit. p. 23.

${ }^{49}$ Las cartas abarcan un período breve de tiempo (desde mayo de 1634, con alguna un poco anterior, hasta finales de 1635), pero esto otorga una gran coherencia al conjunto. La mayoría fueron remitidas desde Bayona por Pedro Lorenzo Aguiar; también desde esa misma ciudad escribieron el doctor Colaço y Pedro Rodríguez Fraga, aunque en cantidad muy inferior. Otras cartas proceden de Ámsterdam - aunque fechadas en Amberes- escritas por Diego de Amezquita, de Amberes (Bento Rodríguez Lisboa y Antonio de Espinosa) y Pamplona (Enrique Fernández Coello). Las cartas recogen una información muy valiosa pero, al ser todas ellas originales y manuscritas, en algunos casos su lectura presenta serias dificultades tanto por el tipo de letra, como por el empleo de claves y abreviaturas y por la mezcla indiscriminada de términos portugueses y castellanos. Todas se encuentran en ADC. Inq. Leg 728, expt 1222. Diversas aclaraciones a las cartas se contienen en Ibíd.. Leg 770, expt 1596.

50 Ibid. Leg 453, expt 6284. Pedro Lorenzo Aguiar era natural de Vila Real al igual que la familia Pato. En 1624, instalado ya en Castilla, fue apresado por el Santo oficio de Córdoba y quizás este tropiezo fuese lo que le empujó a pasar a Francia. Instalado en Bayona, desarrolló allí una intensa actividad como agente de diversas redes comerciales transnacionales de las familias de numerosos hombres de negocios portugueses, como Luis Fernández Pato, Tomas Rodríguez Enríquez o Fernando Montesinos. 
Pedro Lorenzo Aguiar remitía a Fernández Pato diferentes productos textiles (cambrays, holandas, fustanes, anascotes, picotes, corchetes, navales, cintas y bayetas), cuyo origen no aparece precisado pero, por el tipo de algunos de los tejidos, podemos suponer que procedían de telares holandeses ${ }^{51}$. En diversas misivas, Lorenzo Aguiar decía estar esperando mercancías o informaba haberlas recibido recientemente, probablemente procedentes de Holanda. Una vez en su poder utilizaba diferentes vías para introducirlas en la Península. Una de ellas era remitirlas por mar hacia Galicia cuya costa era zona propicia para el contrabando ${ }^{52}$. Los puertos gallegos, especialmente el de La Coruña, eran un lugar conocido para la familia Pato ya que en tierras gallegas comenzaron sus negocios $^{53}$. En 1629, un jovencísimo Luis Fernández Pato se hizo cargo de la dirección de los negocios familiares en Galicia. Hasta 1631, fecha en que se trasladó a Madrid, recibió en La Coruña mercancías como paños o bayetas que vendía a comerciantes locales y, al mismo tiempo, recibía productos como zumaque, aceite, pasa, azúcar, limones, algodón o tabaco remitidos desde Sevilla, Málaga o Aveiro y que reexpedía a sus familiares y agentes en Ámsterdam y Hamburgo ${ }^{54}$.

Tras el traslado de Luis Fernández Pato a Madrid, la ruta gallega perdió importancia en beneficio de la Francia con Castilla por el País Vasco y Navarra. La mayoría de las cartas hacen referencia a esta vía. El camino vasco-navarro ya

51 WILSON; Ch. y PARKer, G. (Eds): Una introducción a las fuentes de la historia económica europea. 1500-1800. Madrid 1985. pp. 105-107. GlamanN, K.: Op cit. p. 392.

52 Carta de 13/IV/35 de Pedro Lorenzo Aguiar desde Bayona. ADC. Inq. Leg 728, expt 1222.Según un memorial, «por las costas de Galicia (...) entran por cada río en cualquier fusta pequeña, metiendo y sacando cualquier cosa con más comodidad que en ninguna otra parte porque todos son portugueses». AZEvedo, L. d': Historia dos Cristãos Novos portugueses. Lisboa 1925 (Reimpresión Lisboa 1989) pp. 462-63. ISRAEL, J.I.: Spain.. Op cit. p.20. Hacia 1623 el puerto de La Coruña era uno de los puntos en los que, según el veedor Martín de Arostegui, debía extremarse la vigilancia para evitar el contrabando. AGS. Estado. Leg 2847.

53 Gonzalo Díaz Pato, tío de Luis, era en 1592 mayordomo del Deán y Cabildo de la catedral de Santiago, cargo que también ocupó su hermano Antonio. Ambos arrendaron juntos numerosas rentas eclesiásticas. También se dedicaron a pasar moneda falsa por las costas gallegas. En 1621 Gonzalo, presionado por la Inquisición, pasó a Ámsterdam y Antonio le siguió dos años después, quedando su hermano Pedro al frente de los negocios familiares y, cuando este también partió hacia las juderías del norte de Europa.

${ }^{54}$ ADC. Inq. Leg 770, expt 1596. Sus intereses en Galicia eran muy amplios, como indican sus viajes de negocios a Santiago de Compostela o a Orense «donde bizo un negocio y cuenta con el Obispo D. Diego de Zúñiga y Sotomayor». También viajaba a tierras castellanas (Valladolid o Rioseco), lusas (Viana, Oporto o Aveiro) y andaluzas (Sevilla). Sebastián Lorenzo le envió desde Málaga a La Coruña una partida de zumaque y otra de pasa. La de pasa iba consignada para Gonzalo y Manuel Fernández Amezquita, vecinos de Hamburgo (primos hermanos de Luis Fernández Pato, afincados a caballo entre Hamburgo y Ámsterdam). Hacia 1630 Luis Fernández Pato tenía dispuestos para exportar desde la Coruña 11.000 arrobas de azúcar, 3.500 libras de algodón y 4.000 quintales de truchuela. Ibid. Leg 445, expt $6292 \mathrm{G}$

Hispania, LXI/3, núm. 209 (2001) 1017-1050 
lo había sido usado anteriormente, al menos desde $1628^{55}$, ofreciendo dos alternativas desde Francia, una marítima hasta los puertos vascos y otra terrestre atravesando Navarra. El primer itinerario era el usado cuando se obtenían licencias y pasaportes, frecuentemente falsos y remitidos desde Castilla, o cuando las mercancías eran muy voluminosas. En una carta enviada desde Bayona a fines de 1634, Pedro Lorenzo Aguiar relataba las gestiones que estaba llevando a cabo para obtener testimonios que le permitiesen meter una partida de productos textiles en Castilla. Decía haber recibido cuatro fardos de anascotes y no saber por dónde remitirlos porque había avisado al agente en San Sebastián, Manuel de Amezquita, "que bable con el juez del Almirantazgo que ba de dar dicho testimonio para que dé licencias» pero «no bay orden para poder enviar porque no quieren aprobar el testimonio por bueno y todo está empantanado». La seguridad antes de enviar las mercancías debía ser total porque según confesaba el propio Aguiar «no está el tiempo para riesgos». No obstante, sus agentes tenían buenos contactos en los lugares necesarios y, por ejemplo, Manuel de Amezquita era amigo del juez del Almirantazgo y gracias a ello «alcanzaba cualquier cosa» ${ }^{56}$.

El itinerario terrestre por Navarra era usado preferentemente cuando no se obtenían las licencias oportunas en Castilla; «por no baber orden de poder ir por San Sebastián irá por Pamplona» decía Pedro Lorenzo Aguiar en enero de $1635^{57}$. En la ciudad navarra contaban con agentes como Bernardo de Eguiarreta o Enrique Fernández Coello que conducirían las mercancías hasta Castilla. Cualquiera que fuese el camino elegido, terrestre o marítimo, el último paso era atravesar los puertos secos que separaban los territorios forales de Castilla. Este último trámite era el más fácil gracias a la connivencia que existía con los agentes de la renta de los puertos secos, en estos años administrada por el portugués Duarte Coronel Enríquez. Una muestra de la estrecha relación entre arrendadores y mercaderes la encontramos en la petición que Pedro Lorenzo de Aguiar dirigió a Luis Fernández Pato para que hablase con Duarte Coronel Enríquez en Madrid a fin de que quedasen libres siete fardos que le habían embargado en Miranda ${ }^{58}$. Otros muchos mercaderes portugueses realizaban similares operaciones comerciales, bien por los puertos vascos, bien por Navarra ${ }^{59}$. Las razo-

ss Fermín de Eguiarreta (vecino de Pamplona y posiblemente pariente de Bernardo de Eguiarreta uno de los agentes más activos de los mercaderes portugueses en la capital navarra), reclamaba en 16354.288 reales de plata por las mercancías que había pasado a la familia Pato desde esa fecha. Ibid. Leg 728, expt 1222. Carta de Enrique Fernández Coello. Pamplona 18/X/35.

56 Ibíd.. Carta de Pedro Lorenzo Aguiar. Bayona 15/XII/34. En otra carta del mismo de 30/VI/34 decía no poder enviar cien piezas de anascotes «por que no acaba de llegar un testimonio que tengo pedido». En otra de 19/I/35 comentaba que no podía remitirle unas cintas por no poder obtener licencias.

57 Ibid. Bayona 5/I/35.

58 Ibid. Bayona $5 / X / 35$.

59 Joseph Sánchez, alias Joseph Falcón, un portugués avecindado en Peyrehorade confesaba ante el Santo Oficio que los puertos más usuales para la entrada de mercancías eran los de Aragón y Navarra. AHN. Inq. Lib 1105, fol 301. En 1633 el Licenciado Juan de Fonseca, vecino de Ruan, 
nes para esta preferencia ya nos son conocidas. A factores como la complicidad con los arrendadores de los puertos secos de Castilla, en su mayoría portugue$\operatorname{ses}^{60}$, hemos de añadir otros como las facilidades que para el contrabando proporcionaban las peculiaridades forales de Navarra ${ }^{61}$ y la desaparición de los navíos ingleses, muy usados por su condición de neutrales, como consecuencia de la guerra hispano-británica (1625-1630)62.

No sólo las rutas que atravesaban los Pirineos o surcaban las aguas del golfo de Vizcaya eran usadas en este comercio. Muchos otros puertos recibían navíos que, con banderas de países neutrales, británicas o hanseáticas preferentemente, transportaban mercancías de origen holandés ${ }^{63}$. Entre los puertos usados para este fin destaca, entre otros, el de Málaga ${ }^{64}$. En 1623 se incautaba allí

decía que usabe que los dichos judíos y los demás de la parte de Hamburgo, Holanda y Amberes van y vienen de España a sus tratos y contratos (...) y los puertos más ordinarios, por donde entran son los de Vizcaya y Pamplona». Ibid, Leg 178, expt 5.

60 Diego de Acosta Blandón era gobernador de los diezmos de la mar por Duarte Coronel Enríquez y en 1630 viajó desde Vitoria Bayona «a hacer conducir las mercadurias que venían de Francia». ADC. Inq. Leg 480, expt 6500. El propio arrendador Duarte Coronel Enríquez había ido un año antes a San Juan de Luz y Bayona «a disponer con los mercaderes de todas las naciones el trato con España». Ibid. Leg. 445, expt 6238. IsRAEL, J. I.: Spain.. Op cit. p. 42 y La judería.. Op cit. pp. 134-135.

${ }^{61}$ Las Cortes de Navarra mantuvieron una dura pugna con el Almirantazgo y la administración real sobre el contrabando y su jurisdicción. Los navarros argumentaban que «el sustento y conservación del reino consiste solamente en la libertad [de comercio] del Reino" por lo que se oponían a cualquier intento de control. AGS. Estado. Leg 2847. En Pamplona existía una nutrida colonia de mercaderes portugueses, entre los que destacaba la familia Fernández Coello. Pedro Álvarez, el hijo de Bento Luis, fue enviado por su padre a los once años a casa de su agente en Pamplona, Enrique Fernández Coello, para aprender el negocio. ADC. Inq. Leg 453, expt 6284. A partir de 1635, con el inicio de la guerra con Francia y el subsiguiente bloqueo comercial, arreciaron los problemas por la interdependencia económica entre los navarros y sus vecinos del otro lado de los Pirineos. DoMINGUEZ ORTIZ, A.: Guerra económica.. Op cit. pp.108-110.

62 ISRAel, J. I.: Spanish wool.. Op cit. pp. 204-205. El vacío dejado por la ausencia de los buques británicos en este período fue ocupado por navíos franceses.

${ }^{63}$ El capitán Esteban Ares de Fonseca, quien tras su marcha de Ámsterdam se convirtió en uno de los principales malsines del decenio de los treinta, afirmaba que venían a España muchos navíos, como los de Hamburgo, que en realidad eran holandeses y todas sus mercancías confiscables. Ibíd.. Lib. 1104. Israel recoge noticias de la facilidad con que el Senado de Hamburgo otorgaba certificados a barcos y mercancías, hasta tal punto que la Corona española llegó a enviar agentes a los puertos hanseáticos para vigilar la licitud de las mercancías embarcadas hacia la Península. ISRAEL, J.I.: Spain.. Op cit. pp. 18 y 19.

64 Málaga ganó en población y comercio durante el siglo XVII. Sus exportaciones de aceite, almendras, pasas o vinos eran muy apreciadas en Holanda desde donde se remitían al puerto andaluz ropas, maderas o cereal báltico. El puerto malagueño servía también como almacén para el comercio con Berbería. En esta ciudad se concentraba una nutrida colonia de mercaderes portugueses conversos. Castillo Pintado, A.: El gran comercio.. Op cit. pp. 344 y 363; IsRael, J. I.: Spain.. Op cit. pp. 10 y 11 e Ibid: «Some further data on the Amsterdam sephardim and their trade with Spain during the 1650's» en Studia Rosenthaliana (Amsterdam) 14 (1980) pp. 7-19. La colonia

Hispania, LXI/3, núm. 209 (2001) 1017-1050 
un navío de Saint Malo con paño holandés y moneda falsa, enviado por judíos portugueses de Ámsterdam (Jerónimo y Duarte Rodríguez Méndez) y, poco después, se incautaba un buque hanseático cargado de madera procedente de Ámsterdam ${ }^{65}$. La presencia de navíos británicos en este puerto está también confirmada por diferentes testimonios ${ }^{66}$. Estos buques, cualquiera que fuese el pabellón bajo el que navegasen, "venían a trocar pasas y vino por otras mercadurías». Ejemplo de esto sería Sebastián Lorenzo, agente de la familia Pato en Málaga, quien remitía pasas y vino a Hamburgo en los mismos navíos que le habían traído desde allí una partida de bayetas con destino a Toledo y Madrid ${ }^{67}$.

Entre los receptores de estas mercancías predominan los mercaderes de grueso afincados en Madrid e integrados en extensas redes comerciales de base familiar. Muchos de los nombres nos son ya conocidos, como los de los hermanos Rodríguez Madrid ${ }^{68}$; Bartolomé Febo y su socio Juan Núñez Saravia ${ }^{69}$; Manuel Cortizos ${ }^{70}$ o Jorge Enríquez. Este último, miembro de una familia extendida en la que su hermano Manuel de Acuña (alias David Ergas) se situaba en Ámsterdam; otro hermano, Nuño Enríquez, actuaba en el suroeste francés y él y su hermano Baltasar Enríquez, socio y amigo de Núñez Saravia e involucrado en la red de contrabando de 1621, estaban afincados en Madrid formando «una misma compañía de tratos comerciales» ${ }^{11}$. Según el testimonio de su tío, Nuño Enríquez iba mucho a La Rochelle por mercancías que después remitía a San Juan de Luz, desde donde su agente las enviaba a San Sebastián a Juan Pérez de Beroiz, encomendero de los Enríquez, quien las remitía a Madrid. Las mercancías procedían de Manuel de Acuña. El testigo incluso afirmaba que «en

de mercaderes extranjeros en Málaga también incluía flamencos, británicos y alemanes. ADC. Inq. Leg. 476, expt 6489.

6s ISRAEL, J. I.: Spain. Op cit. p.19.

${ }^{66}$ ADC. Inq. Leg 461, expt 6341.

${ }^{67}$ Ibíd.. Leg. 532, expt 6807 y Leg 445, expt 6292 G. En otras ocasiones estos navíos no traían mercancías porque el importe de los productos que cargaban en Málaga se pagaba por medio de letras a favor de Luis Fernández Pato en diferentes lugares.

${ }^{68} \mathrm{AHN}$. Inq. Leg 178, expt 5. Mantenían una intensa relación comercial con portugueses judaizantes de Ruan, como Antonio de Cáceres y, a través de ellos, con Ámsterdam.

69 El estudio de la red comercial de Febo y de sus negocios ya fue realizado por N. Bröens, quien puso de relieve su relación con la comunidad judía de Ámsterdam donde residían algunos de sus familiares y su participación en negocios de contrabando. Sólo vamos a añadir un dato, el propio Bartolomé Febo reconocía haber perdido mucha hacienda por pleitos «y condenaciones del Almirantazgo». AHN. Inq. Leg 146, expt 4. Sobre Febo BRÖENS, N.: Op cit. pp. 54-61 y Caro BAROJA, J.: «El proceso de Bartolomé Febo» en Vidas poco paralelas. Madrid 1981. pp. 13-49. Sobre Núñez Saravia, BRÖENS, N.: Op cit. pp. 51-62 y AHN. Inq. Leg 178, expt 5; Leg 171, expt 4. También Dominguez ORTIZ, A.: «El proceso inquisitorial de Juan Núñez Saravia, banquero de Felipe IV» en Hispania (Madrid) 61 (1955) pp. 559-581 y CARRASCO VAZQUEZ, J: Op cit.

${ }^{70}$ En $17 / \mathrm{V} / 29$ el Almirantazgo le embargó 17 piezas de Holanda por valor de 4.080 reales y 168 gruesas de botones de seda por valor de 1.068 reales, acusándole de ser mercancías de contrabando. AHPM. Prot n1 5658 .

${ }^{71}$ AHN. Inq. Leg 144, expt 15. 
cada mazo de bilo las tres partes del eso eran de moneda falsa y lo mismo era en los balones de resma de papel blancos 72 . Toda una red en pleno funcionamiento, como imaginamos que serían las de los anteriormente mencionados o las de otros muchos mercaderes portugueses.

De todos estos datos podría obtenerse una imagen de los mercaderes lusos próxima a la de los más conspicuos contrabandistas. Sin embargo, aun cuando es innegable su activa participación en este tipo de comercio, lo cierto es que una buena parte de las mercancías que recibían del exterior llegaban aparentemente cumpliendo los requisitos legales, fuese cual fuese su origen. Hay numerosos testimonios de autorizaciones a los agentes para pagar diversos impuestos aduaneros como el diezmo del mar prueba inequívoca de que muchas de las mercancías que se importaban reunían formalmente las condiciones legales lo que les confería una apariencia de honrados mercaderes ${ }^{73}$.

\section{D) LOS EMBARGOS DE 1628 Y 1640}

Los esfuerzos del Almirantazgo por yugular el comercio ilícito no parecían dar los resultados apetecidos, ya que la entrada de productos procedentes de Holanda seguía produciéndose por las vías más diversas. No obstante, los esfuerzos de los agentes reales lograban en algunas ocasiones importantes éxitos con la captura de valiosos cargamentos de mercancías ilegales. A finales de 1628 las autoridades navarras y las del Almirantazgo embargaron, en Pamplona y Madrid respectivamente, una gran cantidad de mercancías que habían entrado fraudulentamente desde Francia. Todos los mercaderes afectados por este embargo eran portugueses.

El valor de lo incautado rondaba la respetable suma de cien mil ducados. Temerosos quizá de perder en su integridad tan valioso cargamento, los mercaderes afectados decidieron negociar con la Corona para tratar de lograr una «composición», aprovechándose de las siempre apremiantes necesidades económicas de la Monarquía. El día 7 de enero de 1629, Fernando Montesinos y Jorge Enríquez, por ellos mismos y como «diputados nombrados por los hombres de negocios mercaderes de la nación portuguesa", presentaron una petición ante el Consejo de Hacienda buscando una salida negociada al problema ${ }^{74}$. Afirmaban en esta

72 Ibíd.. Antonio de Acosta Paz, vecino de Ruan, declaraba que «Jorge Enríquez iba y venía a San Juan de Luz con mercadurías y esperaba que llegase su bermano Nuño Enríquez de la feria de La Rochela con mercadurias para venirse con ellos a Castilla». Ibíd.. Lib 1103.

73 Entre otros muchos ejemplos podemos citar el poder dado por Fernando Montesinos en Madrid en 4/V/32 a Domingo de Guerena, vecino de Vitoria, spara que me pueda obligar para el pago de diezmos de la mar y puertos secos por las mercancias que vinieran desde San Sebastián y otros puertos». El poder también le autorizaba para pagar los derechos que correspondiesen a las lanas, añinos, paños y otras cosas que le remitiese para despachar por el puerto de la ciudad de Vitoria. AHPM. Prot n1 5661.

74 AGS. CJH. Leg 656.

Hispania, LXI/3, núm. 209 (2001) 1017-1050 
petición que tanto ellos como sus representados habían «tratado y contratado en estos reinos cantidad de mercadurías que han entrado en ellos», pero las últimas medidas reales, en especial la cédula de $16 / \mathrm{V} / 28$, «les ban hecho y hacen muchas molestias y agravios denunciándoles las dichas mercadurias y obligándoles a dar fianzas y seguir pleitos». Estas quejas respondían, probablemente, al aumento de la presión ejercida por el Almirantazgo sobre el comercio fraudulento. Al mismo tiempo, nos indica que una buena parte de las mercancías importadas por mercaderes portugueses tenían un origen cuando menos dudoso, lo que provocaba una cascada de pleitos, especialmente tras el endurecimiento de los requisitos para el comercio exterior que impuso la cédula de 1628. Efecto quizá de este reforzamiento de la vigilancia fueron estos embargos realizados, tanto en Navarra como en Madrid, por el Virrey de Navarra y el Almirantazgo respectivamente.

Seguían lamentándose los peticionarios del gran daño que al comercio y trato e, incluso, a la Real Hacienda había producido el embargo de sus mercancías. Supuestamente movidos por su celo y su deseo de servir al Rey, ofrecían que, a cambio de las mercancías incautadas y el sobreseimiento de los procedimientos incoados contra ellos por el Tribunal del Almirantazgo, darían a la Real Hacienda, en una vez, veinte mil ducados de plata quince días después de recibir las mercancías ${ }^{75}$. Además, prestarían otros cien mil ducados de vellón sin interés para la provisión de la Real Armada a pagar en cuatro meses ${ }^{76}$. El Consejo de Hacienda envió al día siguiente una consulta al Rey informándole de la oferta de los portugueses. Los consejeros propusieron aceptar la propuesta pues:

«aunque pretensiones semejantes ofrecen dificultades (...) el aprieto de los tiempos y los casos sucedidos de falta de hacienda y que cuando ella está disminuida sobrevienen necesidades que ponen en opinión de mayores gastos no queda libre la elección y es fuerza pasar por algunos inconvenientes»

Las necesidades económicas de la Corona jugaban a favor de los contrabandistas y el Rey aceptó su oferta. El 9 de enero de 1629, ordenó suspender las causas y el día 20 del mismo mes se dio licencia a los mercaderes portugueses

75 Si el valor de las mercancías incautadas superaba los cien mil ducados de plata se comprometían a pagar «por la tal demasía a razón de veinte por ciento en plata». En otra oferta posterior añadieron al donativo otros mil ducados más en vellón que serían dos mil si el valor de las mercancías excedía de los cien mil ducados, amén del veinte por ciento del sobrevalor.

${ }^{76}$ La mitad se pagaría en Madrid y la otra mitad en Sevilla. También se comprometían a incrementar esta cantidad si el valor de lo secuestrado superaba los cien mil ducados a razón de un veinte por ciento sobre el exceso. Otra cláusula de la oferta pedía que la tasación de lo secuestrado se hiciese «ante escribano sin que los jueces y ministros que han procedido en las causas tengan en qué intervenir en cosa alguna pues sólo a de servir para reconocer si montan más de los dichos cien mil ducados». Tan extraña condición debe entenderse como un intento de ocultar a los agentes del Almirantazgo el origen holandés de muchas de las mercancías lo que de conocerse habría supuesto un agravamiento del delito que se le imputaba, al realizar la tasación un escribano éste tan solo se interesaría por el valor de las mercancías y no por su procedencia.

Hispania, LXI/3, núm. 209 (2001) 1017-1050 
para traer a Madrid las mercancías denunciadas en Navarra previo pago de los derechos correspondientes ${ }^{77}$.

Admitidos el donativo y el préstamo a cambio de las mercancías embargadas y del perdón, se sucedieron las negociaciones para ultimar detalles como los plazos de entrega de lo incautado, de las pagas de lo prometido y otros pormenores. En una consulta dirigida en 1 de febrero al Rey sobre estos temas menores se recogía el voto singular de uno de los consejeros, D. Miguel de Ipeñarrieta. Este opinaba que «no tiene por útil ni conveniente que se haga la composición prevista» expresando su criterio más favorable a mantener el bloqueo económico que a resquebrajarlo mediante concesiones de este tipo generadas por la momentánea falta de dinero en las arcas reales. Los argumentos en los que fundaba su oposición eran claros. En primer lugar, las mercancías valían mucho más de lo que se ofrecía. En segundo lugar consideraba seguro que los mercaderes perderían todos los juicios que tenían pendientes al ser estas mercancías «fabricadas y traídas de las Islas Rebeldes de Olanda y Zelanda y otras tierras de enemigos». De este modo todo lo incautado pasaría al fisco real y esto, según él, «se comprueba con la gran instancia que se bace por parte de los dueños de ellas». Completaba su razonamiento diciendo que «si fueran de buena entrada y permitidas trataran de ella con más remisión» (esto explicaría la negativa de los mercaderes a la presencia de jueces en la tasación del valor de lo incautado). En tercer lugar, de realizarse la composición, los denunciadores quedarían sin su recompensa por lo que se desanimarían e incluso puede que «ayudaran a la entrada en el reino de cualesquiera mercadurías de contrabando concertándose con los que las traen». Por último argumentaba que

\begin{abstract}
«no tiene por merecedores del favor de ella [de la composición] a los que la pretenden pues siendo vasallos de V.Md. y contra su real servicio y contra mandatos expresos de V.Md. tratan y contratan con los rebeldes y enemigos acomodándoles sus mercadurías y granjerías y remitiéndoles y llevándoles de estos reinos el oro y la plata de su precio y enriqueciéndolos con esto y acrecentándoles las fuerzas para sustentar la guerra que hacen a V.Md.» ${ }^{78}$.
\end{abstract}

Resulta innegable que Ipeñarrieta no sentía ninguna simpatía por los portugueses a los que consideraba, entre otras cosas, una quinta columna de los holandeses y por ello peligrosos enemigos de la Corona. Algún tiempo después, en 1638, este furioso antiportugués compartiría asiento en la Junta que se formó para tratar temas de moneda con Sebastián Cortizos, uno de los miembros más relumbrantes de la comunidad lusa en Castilla. Sin duda la rueda de la vida giraba deprisa en aquellos años.

Las opiniones de Ipeñarrieta no eran un fenómeno aislado. En otra consulta posterior, de 27 de febrero, se contenía un papel enviado por el Virrey de $\mathrm{Na}$ -

77 AHN. Consejos. Leg 13.195, expt 1 y 6.

78 AGS. CJH. Leg 656.

Hispania, LXI/3, núm. 209 (2001) 1017-1050 
varra manifestando su oposición a la composición. Justificaba esta opinión apelando al fuero de aquel reino según el cual «no pueden sacarse las causas de allí» por lo cual era en Navarra donde debían verse estas causas de contrabando sin que la composición con la Corona pudiese anularlas ni hacer que se devolviesen las mercancías embargadas. El papel del Virrey de Navarra abrió un vivo debate en el seno del Consejo. Los marqueses de la Puebla y de los Trujillos defendieron la supremacía del poder real sobre los fueros de Navarra y, por tanto, el que fuese competente para suspender las causas y devolver las mercancías para mantener así el acuerdo a que se había llegado con los portugueses ya que era «tiempo de necesidades urgentes de provisiones». Maliciosamente sugerían que quizá la oposición navarra "podría ser el haber puesto los ojos en que las mercadurías y dineros se queden y repartan en aquella tierra sin que la Real Hacienda ni las provisiones en que está cargada goçen nada de ello». En cuanto a las criticas del Virrey de Navarra sobre la inoportunidad de la negociación con los portugueses reclamaban la competencia exclusiva del Consejo para decidir si convenía o no aceptar la composición. Además, para ellos era muy difícil diferenciar las mercancías lícitas de las ilícitas por lo que no creían que se pudiesen ganar los pleitos en caso de no acceder a su suspensión ${ }^{79}$. Concluían, pues, que era «útil el concierto tomado con los portugueses» ya que «el dinero de está composición está aplicado a causas urgentes con tanto peligro en la tardança que podría ser irreparable el daño».

Los opuestos al acuerdo dentro del Consejo como los licenciados Diego del Corral, Belenguer de Aoiz y Miguel de Ipeñarrieta apoyaron la postura del Virrey de Navarra. Para ellos era necesario «que estos mercaderes tengan el castigo merecido de su delito y que den ejemplo para que ninguno se atreva a contravenir los reales mandatos» y al mismo tiempo para no defraudar a los denunciantes dejándoles sin su justa recompensa «viéndose frustrados del premio». Consideraban que el perdón a los portugueses estaría en contradicción con las leyes particulares y fueros de Navarra y convenía respetarlos en este tipo de causas para involucrar activamente a los navarros en la persecución del contrabando «siendo como es [Navarra] la llave de estos reinos (...) no dando lugar a que por aquella puerta se defrauden los reales bandos». Por último, insistían en que «no tienen por merecedores de composición a estos mercaderes» por considerarles traidores a la Corona y favorecedores de los enemigos de la Monarquía.

Los apuros financieros del Rey debieron de pesar más que las consideraciones negativas hacia la composición de algunos de sus consejeros ya que finalmente se aceptó la oferta de los mercaderes portugueses. El día 15 de marzo de

79 Ibíd.. Consulta de 27/II/29. Los marqueses de la Puebla y Trujillos ofrecían un curioso razonamiento sobre la dificultad de detectar cuáles eran las mercancías ilícitas: «viene a baber mucha incertidumbre en las condenaciones y aunque las lícitas que vienen envueltas con las ilícitas se confiscan llega pocas veces este caso porque por ser las provanças de las ilícitas incierta y congetural aunque llegue a grado de condenarse por ellas las ilícitas".

Hispania, LXI/3, núm. 209 (2001) 1017-1050 
1629 se tomaba el asiento que contenía dicha composición ${ }^{80}$. Pese a haberse alcanzado un acuerdo, la resistencia de los navarros a desembargar las mercancías continuó de modo solapado. Así el mes de julio el Consejo se hacía eco de una petición presentada por Jorge Enríquez y Fernando Montesinos en la que se quejaban de que, a pesar de las tres órdenes sucesivas que había enviado el Rey al Virrey de Navarra para la remisión de las mercancías embargadas a Madrid, ésta aún no se había realizado. El Rey se vio obligado a dictar otra Real Cédula en 7 de agosto de 1629 reiterando la orden de traer a Madrid todas las mercancías embargadas en Navarra «y no se pongan más dilaciones» ${ }^{81}$.

La totalidad de los participes en esta operación pertenecían al grupo de los mercaderes de lonja (algunos ya podían ser considerados plenamente hombres de negocios, otros no) procedentes de las comarcas del noreste luso ${ }^{82}$ asentados en Castilla desde fines del XVI y principios del XVII. El comercio, a veces comenzando en niveles modestísimos, había sido el origen de su fortuna merced a los apoyos que les proporcionaban una amplia red de agentes y corresponsales, muchos de ellos familiares, como ya tuvimos ocasión de ver. Las oportunidades de lucro que ofrecía el comercio ilícito tampoco habían sido desaprovechadas en estrecha relación con familiares instalados en las juderías holandesas y en los puertos el suroeste galo y muchos de ellos habían participado en la red de contrabando descubierta tras el final de la Tregua y en otras operaciones fraudulentas ${ }^{83}$. Su grado de enriquecimiento no les permitía aún acceder directamente al gran negocio de los asientos y los arrendamientos de rentas reales. Se conformaban con la participación en los asientos de los poderosos banqueros lisboetas que acababan de sustituir a los genoveses como financieros de la Mo-

${ }^{80}$ Casi todos los mercaderes portugueses cuyas mercancías habían sido secuestradas participaron en el asiento. Algunos se negaron pese a tener alguna parte en los productos embargados lo que dio lugar a varios pleitos ante el Consejo de Hacienda como en el caso de Antonio Enríquez Gómez y Jerónimo Fonseca. Junto a Jorge Enríquez y Fernando Montesinos participaron Baltasar Enríquez, hermano de Jorge; Vasco Fernández Díaz, paisano y amigo de Montesinos; Domingo Coutiño; Pedro Fernández Pato, tío de Luis Fernández Pato; Bartolomé Febo; Francisco de Amezquita, hermano de Efraín Bueno, yerno del doctor Téllez, y Antonio Correa. Ibíd.. CC.GG. Leg 123 y CMC.

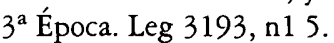

81 AHN. Consejos. Leg. 13.195, expt 98.

82 Dos eran oriundos de Vila Flor (Montesinos y Vasco Fernández Díaz), tres de Trancoso (los hermanos Enríquez y Francisco de Amezquita), uno de Vila Real (Pedro Fernández Pato) y otro, aunque nacido en Madrid, de familia oriunda de Lamego (Bartolomé Febo). Todas estas localidades pertenecen a las regiones de Tras-os-Montes y la Beira Alta. De dos de los participantes no conocemos su origen (Antonio Correa y Domingo Coutiño) pero con toda probabilidad estaría en estas mismas comarcas. Sobre los mercaderes lusos y su afincamiento y enriquecimiento en Castilla véase LÓPEZ BELINCHÓN, B.J.: Op cit..

${ }_{83}$ Así, por ejemplo, Francisco de Amezquita ya había sido acusado en 1613 y 1620 de entrar moneda falsa y sacar plata de Castilla y, al igual que Montesinos, los hermanos Enríquez y Vasco Fernández Díaz habían participado en la red de contrabando descubierta en 1621. CARRASCO VAZQUEZ, J.: Op cit.

Hispania, LXI/3, núm. 209 (2001) 1017-1050 
narquía ${ }^{84}$ o con tomar pequeñas rentas locales individualmente o formando compañía con otros portugueses de su mismo estrato socioeconómico. Este grupo de mercaderes lusos y otros como ellos estarían aún en una fase de acumulación de capital aprovechando los importantes beneficios generados por un comercio exterior no siempre lícito y la posterior redistribución de estas mercancías por un extenso mercado interior. Sin embargo, ya poseían suficiente entidad como para tentar a la exhausta hacienda real con un jugoso donativo y un préstamo en muy buenas condiciones.

Pese a tropiezos como este, el contrabando debió de seguir y aun intensificarse tras el inicio de la guerra con Francia en 1635. La nueva contienda hizo añadir a los productos prohibidos los procedentes del país vecino ${ }^{85}$ y supuso el cierre de la ruta terrestre por Navarra y un parejo crecimiento de la vía marítima. La vigilancia de los agentes reales continuó dando sus frutos y así en abril de 1640 una serie de hombres de negocios portugueses se encontraban envueltos en un buen número de pleitos «por baber metido en estos reinos y sacado fuera de ellos mercadurías de contrabando ${ }^{86}$. Estos procesos eran el resultado de las averiguaciones secretas sobre las correspondencias de los hombres de negocios portugueses con el exterior y la entrada de mercancías prohibidas que a fines de 1639 el Rey había encomendado a José González ${ }^{87}$. Con tal fin se constituyó una junta de la que formó parte también el Inquisidor Adám de la Parra.

La experiencia de 1629, sin duda plenamente satisfactoria para los mercaderes portugueses, hizo que varios de los involucrados en estas causas por contrabando ofreciesen a la Monarquía una nueva composición. A cambio del indulto de sus causas y de que se les devolviesen usus cartas, libros y papeles y se les desembarguen sus bienes, dineros, mercadurías, lanas, añinos y efectos» se comprometían a anticipar cien mil ducados de vellón en Madrid con un ocho por ciento de interés y cuatrocientos mil ducados de plata a cambio de igual cantidad en vellón con un premio del veintiocho por ciento ${ }^{88}$. En la subsiguiente negociación surgió la duda sobre si el pretendido indulto incluiría, como sin duda era el deseo de los portugueses, las haciendas embargadas que pertenecían a portugueses residentes en países enemigos como Francia y Holanda. Para conseguir esto los hombres de negocios ofrecieron trocar otros veinte mil ducados de

${ }^{84}$ Jorge Enríquez aparece como participe de los asientos del licenciado García Yllán. BOYAJIAN, J.: Op cit. p. 209.

8s Reales Cédulas de 4/V/35 y 25/VI/36, entre otras.

86 AGS. CC.GG. Leg 134.

87 AHN. Inq. Leg. 54, expt 10. En un billete manuscrito de José González, fechado en Madrid en 19/XII/39, informaba a la Suprema que el Rey use ba servido de mandar averigüe los excesos que ba babido en sacar bacienda de estos reinos a los enemigos». Según declaraban los propios hombres de negocios sus causas habían sido incoadas «así por el inquisidor D. Juan Adám de la Parra como por cualesquiera jueces nombrados por el señor José González». AGS. CC.GG. Leg 134.

${ }^{88}$ AGS. CC.GG. Leg 134. No sólo pedían el indulto para ellos sino también para sus agentes, cajeros y correspondientes También pedían un 5\% por la conducción. 
plata por vellón con el mismo premio que la anterior propuesta. Finalmente, el 19 de mayo de 1640, se firmó el asiento en el cual los portugueses obtenían todas sus peticiones a cambio de los cien mil ducados anticipados en Madrid y el trueque de cuatrocientos veinte mil ducados de plata a vellón ${ }^{89}$. Los hombres de negocios obtenían también el fuero de asentistas y por lo tanto un juez privativo, cargo que recayó en el licenciado José González, íntimo colaborador de Olivares ${ }^{90}$. El mismo hombre encargado de perseguir sus actividades ilícitas era ahora el encargado de velar por ellos, indudablemente era tiempo de contrastes, todo cambiaba muy deprisa y nada era lo que parecía.

Hasta veintiocho hombres de negocios portugueses participaron en este asiento. Entre ellos se repiten nombres ya conocidos como los hermanos Enríquez, Bartolomé Febo, Luis Fernández Pato, Enrique Méndez y Fernando Montesinos $^{91}$. Muchos de ellos ya habían participado en la red descubierta en 1623, en la composición de 1629 o en ambas. Todos ellos forman un grupo unido por una compleja red de lazos económicos y familiares. Fernando Álvarez Vega, por ejemplo, era suegro de otro de los participes, Andrés de Villegas, el cual a su vez era cuñado de otro, Manuel Lorenzo Madureira (éste era hermano de Juan Núñez Vega, el arrendador de los puertos secos en 1621, y él mismo fue administrador de los puertos de Agreda y Arcos). Muchos se integraban en poderosos grupos familiares como en los casos de Simón Fonseca Piña (cuñado de los hermanos Rodríguez Passarihno), Francisco Rodríguez Penamacor o Antonio y Francisco Méndez Silva.

Aparte de las relaciones familiares también existían entre la mayoría de ellos un tupido entramado de relaciones de amistad. Fernando Álvarez Vega había sido testigo en las defensas de los procesos inquisitoriales de Luis Fernández Pato, Antonia Blandoa (madre. de Andrés de Villegas y suegra de Manuel Lorenzo Madureira, ambos participes en el asiento) y Fernando Montesinos. De este último también fueron testigos de sus defensas otros partícipes como Vasco Fernández Díaz, Guillermo de Lovayna y Simón Méndez Soto (primo de

\footnotetext{
${ }^{89}$ Sobre el reparto de estas cantidades entre los consortes, Ibíd.. Allí se contienen las cuentas presentadas al fenecimiento del asiento. El reparto ocasionó numerosos problemas como atestiguan numerosos protocolos notariales. AHPM. Prot $\mathrm{n}^{\circ} 5055$.

90 BOYAJIAN, J.: Op cit. p. 116. Olivares encargó A José González que se convirtiese en juez privativo de numerosos asentistas portugueses. Además de los comprendidos en este asiento también lo fue en 1635 de Diego Méndez Xímenez y Antonio Méndez Silva, entre otros.

91 AGS. CC.GG. Leg 134. Los participantes en el asiento eran: Simón Méndez Soto, Enrique Méndez, Jorge Enríquez, Duarte de Acosta, Baltasar Enríquez, Antonio y Francisco Méndez Silva, Fernando Montesinos, Andrés López Isidro, Vasco Fernández Díaz, Francisco Fernández Martínez, Fernando Gómez Pardo, Francisco López, Francisco Báez Pinto, Guillermo de Lovayna, Bartolomé Febo, Francisco Núñez Sosa, Luis Fernández Pato, Antonio López Mirandela, Andrés de Villegas, Manuel Lorenzo Madureira, Fernando Rodríguez Penamacor, Jerónimo Felipe, Francisco López Capadocia, Simón Fonseca Piña, Juan Rodríguez Sosa, Duarte López Pereira y Fernando Álvarez Vega. En las negociaciones iniciales también participaron Esteban Odón y Pedro Miranda pero no llegaron a participar en el asiento.
}

Hispania, LXI/3, núm. 209 (2001) 1017-1050 
Guillén de Soto uno de los involucrados en la red de contrabando de 1621) quien también fue testigo de descargo de Bartolomé Febo en su proceso inquisitorial $^{92}$. A su vez Montesinos mantenía relaciones de amistad con Vasco Fernández Díaz y Jorge Enríquez amigo a su vez de Francisco Báez Pinto, Francisco López Capadocia, Fernando Álvarez Vega o Bartolomé Febo y testigo en las defensas de Antonia Blandoa con cuyo marido confesaba haber tenido una gran amistad ${ }^{93}$.

Sólidos lazos económicos unían también a los diferentes miembros de este grupo. El ya citado varias veces Fernando Álvarez Vega participaba en los asientos del licenciado García Yllán al igual que otros implicados en este asunto como Simón Fonseca Piña (agente en Sevilla de García Yllán en los años treinta) o Jorge Enríquez. Otros, como Antonio y Francisco Méndez Silva y Fernando Gómez Pardo, participaban en los asientos de Juan Núñez Saravia. Era este un personaje clave pues muchos de los participantes en el asiento mantenían con él relaciones de negocios y amistad como los hermanos Enríquez, Enrique Méndez, Fernando Gómez Pardo y Bartolomé Febo. Todo este conjunto de vínculos confiere a este grupo una fuerte cohesión interna, una personalidad, que se refuerza aún más con la existencia de otras características comunes como su origen ${ }^{94} \mathrm{o}$ su ascendencia conversa.

Sus trayectorias profesionales presentan, sin embargo, algunas novedades. En su mayoría habían logrado ya enriquecerse lo suficiente con el comercio como para en este momento poder ser considerados plenamente como hombres de negocios, superada ya la etapa que vimos en 1629. Algunos de ellos habían logrado acceder ya a la administración de importantes rentas reales. Por estas fechas Montesinos administraba la renta de las salinas de Galicia y Asturias y ese mismo año tomaba un asiento de más de 100.000 ducados. Otros consortes también administraban rentas como Simón Fonseca Piña quien poseía el arrendamiento del derecho de extracción de lanas amén de haber realizado ya varios asientos; Antonio y Francisco Méndez Silva venían participando desde 1631 en asientos con su cuñado Diego Méndez Ximénez; Francisco López Capadocia era arrendador de la renta del tabaco del reino de Portugal y Francisco Rodríguez Penamacor administraba en 1640 la renta del papel de estraza y tomaba la renta de las salinas de Espartinas en la que dos años después le sustituiría otro de los participantes en este asiento, Andrés López Isidro ${ }^{95}$. Estaríamos, por

92 ADC. Inq. Leg 445, expt 6238 y AHN. Inq. Leg. 146, expt 4.

93 Ibíd.. Leg 452, expt 6273

${ }_{94}^{4}$ De los 28 participes conocemos el lugar de origen de 19 (67.85\%). De estos, un $84.2 \%$ (16) proceden del noreste luso (8 de Tras-os-Montes; 7 de la Beira Alta y 1 de la Beira Baja) y el $15.8 \%$ (3) restante se reparte entre Lisboa (2) y Galicia (1). Sospechamos que los nueve cuyo origen desconocemos eran oriundos también de estas zonas por su tipo de negocios, su biografía, sus amistades y relaciones familiares.

95 AGS. CJH. Leg 1732. Pese a tomar la renta por diez años en 1640 fue sustituido dos años después por Andrés López Isidro. 
tanto, ante un grupo fuertemente cohesionado y, pese a los duros procesos inquisitoriales sufridos por algunos de ellos en los años treinta ${ }^{96}$, estaban adquiriendo un importante papel en las finanzas de la Monarquía.

\section{E) LAS LICENCIAS REALES PARA COMERCIAR. USO Y ABUSO}

Las dificultades financieras de la Monarquía habían facilitado la realización de composiciones con los mercaderes que violaban las prohibiciones comerciales impuestas por la Corona. La búsqueda de dinero para las exhaustas arcas reales y la necesidad de traer a la Península determinados productos del norte de Europa como el trigo báltico o pertrechos navales, obligaron a la Corona a autorizar una cierta legalización del comercio fraudulento mediante la venta de licencias de comercio. Con éstas los mercaderes obtenían autorización para importar productos prohibidos por un valor previamente determinado a cambio del pago a la Real Hacienda de cierta cantidad en metálico que generalmente solía oscilar entre el seis y el diez por ciento del valor de las mercancías autorizadas. Los hombres de negocios lusos interesados en este tipo de comercio aprovecharon esta oportunidad, especialmente tras el inicio de las hostilidades con Francia, en 1635, que hizo más difícil la utilización de sus anteriores circuitos comerciales, sobre todo los terrestres. En 1638 la concesión de licencias había reportado ya a la Corona la importante suma de 225.460 ducados $^{97}$.

Entre los que usaron estas licencias volvemos a encontrar nombres ya muy conocidos por su vinculación a las redes de contrabando. Simón Méndez Soto obtuvo en 1643 una licencia para introducir mercancías de contrabando por los puertos de Bilbao, San Sebastián, Santander, Sanlúcar y Málaga aunque no sabemos su cuantía ${ }^{98}$. Otros participantes en los asientos que hemos visto anteriormente también adquirieron licencias como Antonio López Mirandela99, avecindado ya en Ruán, o Bartolomé Febo quien a cambio del pago de diez mil ducados de plata obtuvo una Real Cédula autorizándole a entrar mercancías francesas hasta un valor de cien mil ducados por los puertos de Cádiz y Bil$\mathrm{bao}^{100}$. Hemos encontrado también algunos casos de licencias otorgadas a agen-

96 LÓPEZ BELINCHÓN, B.J.: Op cit..

97 Dominguez Ortiz, A.: Guerra económica... Op cit. p. 96. LYNCH, J: España bajo los Austrias. 2v. Madrid 1970 (1975), V.II, p. 218 y CASTILLO PINTADO, A.: El gran comercio... Op cit. p. 353.

98 AGS. Contaduría del Sueldo 2. Leg 146. En esta licencia aparecía Antonio López Suazo como su socio.

99 Ibíd.. La licencia la obtuvo en 1653 y en ella se le autorizaba a introducir 50.000 ducados de plata en mercancías francesas por los puertos de Bilbao, San Sebastián y Fuenterrabía. A cambio pagó a la Corona 5.000 ducados de plata.

${ }_{100}$ Ibíd.. Otro ejemplo de una licencia sustanciosa fue la recibida por el flamenco Adrián Páez, muy relacionado con los círculos de hombres de negocios portugueses de donde provenía su propia esposa. En 1642 recibió permiso para entrar por Málaga mercancías de contrabando procedentes de 
tes de conocidos hombres de negocios portugueses lo que nos hace suponer que las mercancías pertenecían a estos antes que al agente cuya capacidad económica no solía ser lo suficientemente importante como para obtener estas licencias. Entre los años 1637 y 1642, Tomás de Santa Coloma, un vecino de Bilbao que fue un activo agente varios hombres de negocios portugueses en ese puerto, recibió varias licencias. Junto a algunas de pequeña cuantía, mercancías por unos cien ducados de valor, aparecen otras de un elevado monto, una de cien mil ducados y sendas de veinte y doce mil ${ }^{101}$, que es muy posible que correspondiesen a mercancías de hombres de negocios portugueses. En 1643, Antonio de Fonseca y Bernardo de Iguiarreta, obtuvieron una licencia para introducir por Cádiz y. Sanlúcar ocho mil ducados de plata en lienzos y mercadurías francesas pagando cuatrocientos ochenta ducados a la Real Hacienda. Ambos beneficiarios eran importantes agentes de hombres de negocios portugueses en los puertos andaluces e Iguiarreta lo había sido hasta mediados de la década de los treinta en Pamplona ${ }^{102}$.

El excelente negocio que suponían las licencias también atraía a mercaderes portugueses afincados fuera de la Península, en Francia o en Holanda, quienes participaban a través de sus correspondientes peninsulares, muchas veces miembros de la red comercial familiar. En 1635, Luis Fernández Pato intentaba «sacar una licencia dando cinco por ciento a $S$. Mgd. para entrar cien mil ducados de mercadurías de contrabando» ${ }^{103}$. De esta licencia, según una carta de Pato a Lorenzo Aguiar, una cuarta parte correspondía a los hermanos Rodríguez Andrade, otra para los Fernández Amezquita y de los dos cuartos restantes uno para él y otro para Pedro Lorenzo Aguiar ${ }^{104}$. Pedro Lorenzo Aguiar era primo de Fernández Pato y su agente en Bayona y los Rodríguez Andrade y los hermanos Rodríguez Andrade se correspondían con él desde Hamburgo y Ámsterdam. Todos los partícipes veían en esta licencia un buen negocio y así Lorenzo Aguiar a escribió a Fernández Pato que «haga lo que pueda para alcanzar la licencia de cien mil ducados que será de mucho provecho»105.

Las licencias también ofrecían un campo idóneo para el fraude mediante su falsificación. Alonso de Uribarri, veedor de la Armada de Flandes, se quejaba en 1644 de las abundantes falsificaciones, «por un pasaporte que se conceda, fabrican los enemigos muchos centenares de ellos con que navegan seguros (...) pues es tan difí-

\footnotetext{
Francia y Holanda por 300.000 ducados de plata de valor en pago de lo cual se comprometía a servir a la Real Hacienda con 30.000 ducados de plata. Ibid. CC.GG. Leg 136.

101 Ibíd.. Contaduría del Sueldo 2. Leg 146. Esta licencia la obtuvo junto con otros mercaderes de Bilbao lo que nos habla del modesto poder económico de Santa Coloma. En 1649 obtuvo otra licencia para introducir por Bilbao y San Sebastián 1.260 quintales de tabaco.

102 Ibid.

${ }^{103}$ ADC. Inq. Leg. 456, expt 6300.

104 Ibid. Leg 728, expt 1225. Los hermanos Fernández Amezquita, que también eran sus primos, se correspondían con él desde Ámsterdam.

105 Ibid. expt 1222. Bayona 9/II/35.
} 
cil la distinción de pasaportes falsos a los verdaderos que los más prácticos y astutos no alcanzan a reconocerlos» ${ }^{106}$. También era frecuente que los poseedores de las licencias importasen más de lo autorizado en ellas ${ }^{107}$. Incluso, había otros métodos más sofisticados de usar las licencias para realizar contrabando de mercancías prohibidas. En diferentes ocasiones, tras ser apresado un navío acusado de contrabando, solía aparecer un mercader esgrimiendo una licencia argumentando que las mercancías que transportaba el navío capturado correspondían a dicha licencia ${ }^{108}$. A fines de 1629 , los corsarios de Fuenterrabía capturaron un navío holandés procedente de Amsterdam cargado con quinientas piezas de bayetas que se dirigía a Bayona. Iniciado el proceso jurídico para obtener los armadores del corso la declaración de buena presa ${ }^{109}$ "salió a la causa Fernando Montesinos y dijo que en virtud de una licencia de Su Majestad [de 18/VI/29] Jorge López de Andrade con poder suyo en Ámsterdam fletó el dicho el navío (...) y que las bayetas eran suyas y que se las entreguen" argumentando que los papeles incautados en el navío eran falsos y los traía por si se encontraba con navíos holande$\operatorname{ses}^{110}$. Durante el juicio, los armadores presentaron numerosos testimonios de que se sacó a relucir el pasado de Montesinos, condenado en diferentes ocasiones por haber metido mercancías de contrabando. Por su parte, Montesinos no dudó en acudir al soborno de oficiales reales y testigos haciendo que algunos de ellos cambiasen su declaración hasta tal punto que algunos le acusaron de que «fue todo embeleco y sobornamiento de testigos y ministros de justicia y cuan gran conocimiento tiene de que el mundo está de modo que todo se conquista con dinero»"11. No conocemos el resultado final de la causa pero parece claro que, pese a sus intentos de demostrar lo contrario, Montesinos trató de utilizar la licencia como cobertura legal ante los ataques de los corsarios vascos a los navíos que transportaban mercancías remitidas por sus agentes desde Holanda hacia sus correspondientes en los puertos del sudoeste francés y que más tarde, bien por mar o por ruta terrestre, pasarían a España. Esta maniobra no fue algo aislado y es muy probable, a tenor de los testimonios citados más arriba, que otros poseedores

106 OTero Lana, E.: Los corsarios españoles durante la decadencia de los Austrias. Madrid 1992, p. 236. El licenciado Diego de Cisneros, que había llegado de Ruan a Madrid en 1633, declaraba que los conversos portugueses instalados en Castilla falsificaban sus libros y «las cartas de fletamientos para la cargazón de los navíos y negociaciones por mar». AHN. Inq. Leg 146, expt 4.

${ }^{107}$ LYNCH, J.: Op cit. V.II. p. 218.

108 OTero LANAS, E.: Op cit. p. 237.

${ }^{109}$ La legislación sobre el corso obligaba a que una vez apresado un barco sospechoso se le llevase al puerto de origen del navío corsario donde tras escuchar a apresadores y apresados se dictaminaba si la presa era buena, es decir, lícita, o no, en cuyo caso había que liberarla. OTERo LANA, E.: Op cit. pp. 238-240.

110 ADC. Inq. Leg 443, expt 6216. Además de la licencia real presento una carta de Jorge de Andrade (sic) desde Ámsterdam dirigida a Martín de Ben en la que le comunicaba el envío de las bayetas en ese navío. La reclamación de Montesinos fue presentada en su nombre por Martín de Ben según poder que le dio en 24/XII/29. AHPM. Prot n1 5658.

${ }^{111}$ Ibid. Leg 728, expt 1226.

Hispania, LXI/3, núm. 209 (2001) 1017-1050 
de licencias la pusieran en práctica. El fraude, aparte el sistema empleado para ejecutarlo, debió de ser lo suficientemente importante como para que en 1647 la Corona diese una Real Cédula (28/IX/47) ordenando a todos los hombres de negocios que registrasen antes de un plazo de dos meses las mercancías que habían metido en el país utilizando licencias reales ${ }^{112}$. Esta medida pone de manifiesto las sospechas reales de que circulaban por los mercados hispanos más mercancías presuntamente introducidas con licencias reales de las que verdaderamente habían sido autorizadas.

En el excelente negocio que las licencias ofrecían estos mercaderes no actuaba en solitario. Toda la red comercial familiar se ponía en funcionamiento para llevar a buen puerto estas operaciones. El cabeza de la casa de negocios en Castilla obtenía la licencia en Madrid lo que reafirma su esencial papel en la estructura de la casa de negocios familiar por su proximidad a los centros de decisión de la Monarquía para de este modo poder participar en las mercedes y jugosos negocios que allí se ventilaban. Una vez en su poder la autorización real enviaba poderes a sus agentes en el exterior, usualmente familiares suyos, quienes se encargaban de adquirirlas. Embarcadas las mercancías, se enviaban a los puertos ibéricos donde diferentes agentes de la casa de negocios tenían poder para recibirlas y encaminarlas donde se les hubiese ordenado a la par que cargaban lanas u otros productos locales como retornos en los navíos que habían traído las mercancías. Por último, estas eran redistribuidas entre los mercaderes minoristas a través de otros miembros de la red comercial ${ }^{113}$. Otros muchos mercaderes también deseaban participar en el negocio y su exclusión era causa de enfrentamientos y envidias como relata el propio Montesinos:

«a muchos portugueses de Ámsterdam y de aquellas partes (...) por las causas de las bayetas que Su Magestad me hizo merced tuve acá y allá muchos envidiosos y habiendo los de allá pedido parte de dicha licencia a mis correspondientes y no se la dan dixeron que yo me quería hacer con todo» ${ }^{114}$.

El asunto debía de ser muy atractivo cuando generaba tantas rivalidades.

Todo lo hasta aquí expuesto nos muestra, a mediados de la década de los treinta, una comunidad mercantil portuguesa fuertemente cohesionada. La mayoría de sus miembros eran judeoconversos originarios de las comarcas del nordeste y practicaban una fuerte endogamia, tanto en los enlaces entre ellos

112 AGS. Contaduría del Sueldo, 2. Leg 146.

${ }_{113}$ Un ejemplo del funcionamiento de una casa de negocios con una de estas licencias en LÓPEZ BELINCHÓN, B. J.: Op cit.

${ }_{114}$ Ibid. Leg. 728, expt 1226.

Hispania, LXI/3, núm. 209 (2001) 1017-1050 
como en sus relaciones socioeconómicas ${ }^{115}$. Estos hombres eran en su mayoría oriundos de las regiones del nordeste lusitano estaba ya firmemente instalado en Madrid a principios de la década de los veinte, coincidiendo con la vuelta de la corte a Madrid. Su éxito económico es atribuible a su papel de intermediarios entre los productos importados, muchas veces fraudulentamente, y los mercados castellanos, merced a su capacidad para participar de modo simultáneo en las grandes redes comerciales internacionales y en las capas inferiores de la contratación, el menudeo. El capitalismo cosmopolita genovés fue incapaz de descender hasta los niveles inferiores del comercio por falta de organización mientras que a los comerciantes castellanos les era muy difícil participar directamente en las redes internacionales con lo que no eran competidores para las casas de negocios portuguesas en este terreno ${ }^{116}$. Su condición de súbditos de.la Corona y la distribución de su red comercial los convertían en el cauce adecuado para abastecer la península de productos del norte de Europa ${ }^{117}$. Esta posición proporcionó a este grupo un nivel de enriquecimiento, por vías licitas e ilícitas, que permitió a muchos de sus integrantes acceder algún tiempo después al sustancioso negocio de los arrendamientos de rentas reales.

El conjunto de todos estos elementos ratifica la existencia de un grupo de hombres de negocios cristianos nuevos portugueses, diferentes, tanto en su origen como en su trayectoria, en su posición social y su comportamiento, de los banqueros lisboetas. No se debe, por tanto, confundir en ningún momento a estos mercaderes provenientes en su mayoría de las áreas ruralizadas de Trásos -Montes y la Beira con los banqueros lisboetas, enriquecidos en el comercio atlántico, que se pondrían al servicio de la Hacienda Real a partir de 1627.

115 Según Montesinos, «lo natural es comunicar (...) con los de su país». Ibid. Leg 443, expt 6216. Sin embargo, entre estos parece que las relaciones eran mucho más intensas las relaciones con los originarios de su mismo pueblo y de zonas comarcanas, ya que entre las solidaridades más fuertes figura la que se establece entre los «emigrados» una vez lejos de su lugar de origen. DURAND, Y.: Les solidarites dans les societes humaines. Paris 1987. pp. 80.81. Estas relaciones son especialmente intensas en lo que define como "grupos de existencia».

116 RuIZ MARTIN, F: Pequeño capitalismo, gran capitalismo. Simón Ruiz y sus negocios en Florencia. Barcelona 1990. "... como el capitalismo cosmopolita no estaba organizado para descender en la Península Ibérica a las capas inferiores de la contratación (...) utilizó la colaboración del capitalismo castellano», p. 22. Ruiz Martín demuestra el carácter subsidiario del capitalismo castellano lo cual dificultó su consolidación y desarrollo.

117 No es el objetivo de este breve trabajo terciar en la polémica sobre la importancia de los embargos. Un resumen de las posturas puede verse en ISRAEL, J. I.: «España, los embargos españoles y la lucha por el dominio del comercio mundial. 1585-1648» en Revista de Historia naval (Madrid) 23 (1988) pp 89-105. En nuestra opinión, resulta innegable que los embargos fueron socavados por agentes como los portugueses merced a la corrupción y a la falta de recursos burocráticos que padecía la Monarquía. Pero, sin duda, el evidente enriquecimiento de intermediarios como los portugueses y la misma necesidad de utilizar sus redes comerciales indicarían que los embargos si afectaron al comercio holandés. Quedaría por determinar el volumen y la importancia del contrabando en relación con las etapas anterior y posterior a los años de embargos para poder precisar su efectividad sobre la economía de las Provincias Unidas.

Hispania, LXI/3, núm. 209 (2001) 1017-1050 
Ambos grupos eran diferentes en su origen, en su evolución y en el papel que, en todos los sentidos, jugaron en la vida castellana. Esto no significa una radical separación entre ambos grupos, al contrario, en múltiples ocasiones se muestran como complementarios detectándose lazos económicos o solidaridades clientelares entre ellos. Recuérdese la intervención de varios de los participantes en este asiento en los del lisboeta García Yllan, y son indudables las conexiones económicas, de amistad o de paisanaje. Sí se puede hablar de papeles socioeconómicos diferentes aunque, insistimos, muchas veces complementarios. Conviene, pues, entender la radical diferencia entre ellos: mientras que los lisboetas llegaron a Madrid ricos y poderosos, ocupando directamente un puesto encumbrado en la Corte los otros hubieron de recorrer un camino más largo, desde posiciones iniciales más modestas, hasta llegar a la riqueza y a las finanzas reales.

Este grupo de hombres de negocios habría aprovechado las oportunidades que ofrecía la guerra económica entre la Monarquía y las Provincias Unidas para enriquecerse mediante el contrabando y las licencias. Esta actuación como «quinta columna» nutrió al antisemitismo hispano de argumentos políticoeconómicos entre los que destacaba a acusación de que los portugueses trataban de usacar la sustancia al reino" en provecho de los herejes holandeses de los que eran aliados. El comercio ilícito de los portugueses socavaba la política de Olivares de asfixia económica de Holanda lo que forzó al Conde Duque a emplear contra ellos, bien es cierto que de modo tamizado, a la Inquisición. A lo largo de la década de la década de los treinta numerosos hombres de negocios lusos involucrados en las redes de contrabando (Montesinos, Jorge Enríquez, Núñez Saravia, Fernández Pato o Bartolomé Febo) fueron apresados por un Santo Oficio. Sus procesos muestran un mayor interés de los inquisidores por sus contactos comerciales fuera de España que por su criptojudaísmo ${ }^{118}$. Sin duda el contrabando fue una actividad muy lucrativa pero que llevaba aparejada numerosos y graves riesgos.

\footnotetext{
118 Sobre esta relación entre Olivares y los conversos LÓPEZ BELINCHÓN, B. J.: «Olivares contra los portugueses. Inquisición, conversos y guerra económica» en PÉrEZ VILLANUEVA, J. y ESCANDELL BONET, B.: Historia de la Inquisición en España y América III, Madrid 2000, pp. 499-530. Diversos autores han insistido en la protección de Olivares a los conversos lusos frente a la Inquisición, un ejemplo de esta visión en EBBEN, M: «Un triangulo imposible: la Corona española, el Santo Oficio y los banqueros portugueses, 1627-1655» en Hispania (Madrid) 184 (1993) pp 541-556 o Zilver, brood en kogels voor de koning. Liden 1.996. Sin embargo, esta opinión es difícil de sostener ante la oleada de prisiones que afectaron a la mayor parte de los negocios conversos lusos afincados en Madrid y vinculados al contrabando (Febo, Enríquez, Montesinos, Fernández Pato, Núñez Saravia y otros muchos). Por tanto, parece obvio que Olivares no dudó en utilizar la Inquisición como arma para amedrentarlos puesto que casi todos los procesados mantuvieron incólume su fortuna y siguieron negociando tras salir de la cárcel. Se trataba más de asustarlos y reconducir sus actividades hacia donde quería la Corona que de eliminarlos.
} 